\title{
Morfología del trabajo en el capitalismo global: trabajo social combinado y desvalorización laboral
}

\section{Humberto Márquez Covarrubias*}

Resumen. En el capitalismo mundial, el trabajo potenciado por la ciencia y la tecnología redunda en una mayor productividad del trabajo social e introduce cambios en los ámbitos de la producción. Las clases sociales se recrean, confrontan y articulan para posibilitar el despliegue de la lógica de valorización del valor y armonizar el trabajo social combinado. En el cuadro general de la estructura de clases sociales emerge una nueva burguesía que concentra el gran capital, capitanea la nueva ola tecnológica, rediseña los planes de negocio y recodifica las funciones de propiedad y gestión empresarial. En la era del capital global, la propiedad por acciones destaca por su carácter rentista y parasitario, la cual es gestionada por funcionarios que se fueron desprendiendo de la función productiva para tornarse un sector especializado y relativamente autonomizado. No obstante, persiste una lumpenburguesía que recurre a métodos nocivos y obscenos, como la violencia y la corrupción. La pequeña burguesía, compuesta por el empresariado o falso trabajador libre, profesionistas e intelectuales, que se presenta como la clase media imbuida en la ideología emprendedora e individualista preñada de ilusiones y aspiraciones maximalistas, pero sucumbe ante las abruptas oscilaciones del ciclo económico. Esa estructura social está soportada por la formación de un proletariado internacional a disposición de los procesos industriales dislocados y la amplia gama de servicios que incluye perfiles laborales y grados de calificación, sobre todo de sectores altamente precarizados. El espectro del trabajo se amplifica con actividades no asalariadas pero subsumido indirectamente por el capital: trabajo campesino persistente, el trabajo de cuidados y la exclusión de jóvenes. En el fondo del abismo se ubica un cúmulo de trabajadores redundante, considerados desechables, desempleados crónicos. La alta precarización y exclusión presiona continuamente hacia la migración forzada, la criminalidad y el trabajo informal.

Palabras clave: capital global, trabajo social combinado, clases sociales, nueva burguesía, nuevo proletariado.

* Docente investigador de la Unidad Académica en Estudios del Desarrollo de la Universidad Autónoma de Zacatecas, México. 


\section{The morphology of labor under global capitalism: Combined social labor and labor devaluation}

Abstract. Under global capitalism, labor power augmented by science and technology results in greater productivity of social labor and introduces changes in the spheres of production. Social classes are reproduced, challenged and extended in order to seek the most logical way to determine the value and efficient organization of social labor. In the overall conception of social class structures a new bourgeoisie emerges, that concentrates large capital, directs the new technological wave, redesigns business planning and recasts the functions of ownership and business management. In the era of global capital, ownership of shares is characterized by its rent-seeking and parasitic nature, which is managed by officials who have gradually shed the productive function to become a specialized and relatively autonomous sector. However, a lumpenbourgeoisie persists that resorts to harmful and distasteful methods, such as violence and corruption. The petty bourgeoisie, made up of businessmen or false free workers, professionals and intellectuals, who present themselves as the middle class imbued with entrepreneurial and individualistic ideology filled with illusions and maximalist aspirations, but succumb to the abrupt oscillations of the economic cycle. This social structure is supported by the formation of an international proletariat at the disposition of dislocated industrial processes and the wide range of services that includes job profiles and degrees of qualification, especially in highly precarious sectors. The broad spectrum of labor is amplified with non-salaried activities but indirectly subsumed by capital: persistent peasant labor, care work and the exclusion of young people. At the bottom of the abyss lies a cluster of redundant workers, considered disposable, chronically unemployed. The high degree of precariousness and exclusion continually pushes them towards forced migration, crime and informal work.

Keywords: global capital, blended social labor, social classes, new bourgeoisie, new proletariat. 


\section{Un punto de observación: el sistema mundial capitalista}

La composición diferenciada del proletariado en la Inglaterra del siglo XIX — entonces epicentro del desarrollo capitalista mundial_-, que fuera analizada por Friedrich Engels en La situación de la clase obrera en Inglaterra (1845), pareciera ser irreconocible en el siglo XXI, merced al mayor grado de diversificación, expansión y heterogeneidad alcanzado por las clases trabajadoras. Con la globalización del capital, la división internacional del trabajo, el intercambio desigual y la explotación del trabajo no sólo se han profundizado, sino que también se han redefinido las relaciones de desarrollo desigual entre los centros y las periferias del mundo capitalista.

La expansión del capital en el tablero internacional desencadena un doble movimiento simultáneo o complementario: la deslocalización industrial en las economías centrales y la relocalización industrial en las economías periféricas. Este fenómeno de gran alcance significa la propagación de las redes de capital global y la formación mundial del valor mediante procesos interconectados que articulan el trabajo social combinado a escala planetaria. Históricamente, una línea de demarcación estructural entre los centros y las periferias ha sido la enorme brecha de productividad en los sectores económicos; sin embargo, la internacionalización del capital acorta esa asimetría, sobre todo en la industria, donde tiende a igualarse, aunque en los servicios se acorta y en la agricultura es donde más persiste (Amin, 1989). Un factor explicativo es la transferencia de tecnología implícita en la relocalización industrial o, dicho de otro modo, en la formación de las cadenas de valor global y la forma desigual que se propaga en los otros sectores. 
Los diferenciales salariales existentes entre las economías desarrolladas y las subdesarrolladas — en condiciones donde pueden igualarse, en algunos sectores, los niveles de productividad - ilustran la perseverancia de niveles disímiles de explotación aun dentro de la trama articulada de la formación de valor a escala global bajo el comando del capital multinacional que tiende a equiparar el modo sociotécnico y la productividad del trabajo. Este sigue siendo un criterio para la exportación de capitales y la formación de emplazamientos productivos en las regiones periféricas, que son reconvertidas en plataformas de exportación para el mercado mundial. La heterogeneidad de las economías subdesarrolladas supone, además, la existencia de una masa amplia de producción mercantil y de trabajo mercantil no capitalistas, que están subsumidos a la órbita de valorización de capital de modos directos e indirectos.

Un tejido productivo con esas características, subordinado al capital global y desarticulado en el plano interno, opera como un mecanismo de transferencia de valor desde las periferias hacia los centros. En las estadísticas oficiales, cuya unidad de análisis son las economías nacionales, pero también en la formación aparente de los sistemas de precios internacionales cada vez más conectados a los mercados financieros especulativos, no es posible advertir este fenómeno (Smith, 2016). Debido a su carácter histórico y estructural, representa uno de los principales factores explicativos de la dialéctica del «desarrollo del subdesarrollo». El trasvase del excedente económico supone la pérdida consistente y sistemática del fondo social de acumulación. En ese tráfago se incluyen las remesas de ganancias, el pago de la deuda externa y la exportación de capitales; pero también la transferencia asociada al comercio intrafirma, el pago de regalías y la extracción de plusvalor derivado de los diferenciales salariales y de 
la superexplotación de los trabajadores (Márquez y Delgado, 2011; Amin, 2012; Dussel, 2014).

La división internacional del trabajo propia de la era del capital global ejerce un papel estratégico en la coordinación del trabajo social combinado. Representa una actualización de la demarcación histórica-estructural entre el mundo desarrollado o central y el mundo subdesarrollado, dependiente y periférico. En la geopolítica del capital, el contenido del trabajo tiene un papel diferenciado en las diversas regiones y países, por ejemplo en China, India, África y América Latina; en los países del norte, en los escandinavos, otro; así como en los países del sur de Europa, como España y Portugal; y, por otro lado, en Grecia también posee otro diseño. La clave está en la prevalencia o no de trabajo inmediato, procesos productivos intensivos en fuerza de trabajo, o de trabajo general, procesos productivos basados en el conocimiento, la ciencia y la tecnología que intensifican la potencia del trabajo. La cartografía capitalista se transforma en la medida en que los componentes geopolíticos del capital y los poderes estatales reacondicionan la arquitectura del poder y de que las fuerzas constitutivas del capital social globalizado y el trabajo social combinado se compenetran, diversifican y alteran.

Uno de los efectos indirectos de la globalización capitalista es que algunos elementos constitutivos del mundo desarrollado, al expandirse en el nivel mundial, se internalizan en los ámbitos del subdesarrollo, pero también ocurre el efecto contrario. Por ejemplo, las redes globales de capital monopolista (Márquez y Delgado, 2011) se amplían más allá del centro y abarcan todos los territorios del sistema mundial e instalan nodos, redes o terminales en las periferias, generan archipiélagos de desarrollo dentro del subdesarrollo, sin por ello trastocar la condición estructural y 
profunda del subdesarrollo de la periferia; en contraste, la emigración forzada y compulsiva de migrantes del Sur al Norte, es decir, de las periferias a los centros, introducen o posibilitan formas de superexplotación en los mercados laborales en los centros dinámicos de la economía global (Felix y Guanais, 2019).

En otro sentido, la revolución industrial cuaternaria, la llamada industria 4.0 (Schwab, 2016), está introduciendo una oleada de digitalización de procesos productivos y distributivos que redunda en mayor desempleo en los países desarrollados, pero la onda expansiva está trasminando a los confines del mundo, por lo que sus efectos tienden a globalizarse. Asimismo, un subproducto de la división internacional del trabajo es la transferencia de la «industria sucia» a determinados países periféricos que absorben los costos socioambientales, como también lo ha sido el comercio de productos obsoletos o «chatarra», la transferencia de tecnologías obsoletas o la colocación de desechos tóxicos.

Históricamente, debido al colonialismo y al imperialismo, como en la actualidad a sus formas renovadas y sofisticadas de neocolonialismo y neoimperialismo, en las periferias el proletariado siempre ha padecido la precariedad y el pauperismo en grados superlativos, por tal razón la superexplotación fue identificada como un rasgo estructural (Marini, 1973) de esos territorios, que ahora tienden a propagarse de las economías subdesarrolladas a las desarrolladas, debido a las políticas neoliberales, cuyo cometido primordial es profundizar el grado de explotación, y a la incorporación masiva de trabajadores inmigrantes. La imagen de conjunto es la tendencia a la generalización de la superexplotación en el capitalismo global. En las periferias, el proletariado moderno emerge, por lo común, luego de la liberación formal del yugo colonial y la implantación de los 
Estados modernos, que en muchos casos significó la abrogación legal de la esclavitud, pero no la superación del subdesarrollo y la dependencia. Resueltamente, la precariedad ha sido la regla, no la excepción, máxime cuando alcanza grados superlativos de explotación, entendida como un tercer método de extracción de plusvalor, que complementa a las formas absoluta y relativa (Marx, 1981).

En el ámbito laboral, es sintomático que las periferias no hayan gestado una «aristocracia obrera», ${ }^{1}$ es decir, un segmento privilegiado de trabajadores calificados, con altas remuneraciones y sindicalizados, prohijado en el marco de un pretendido Estado desarrollista, a la postre un remedo del Estado benefactor de los países desarrollados europeos, cuyos descendientes, aún dentro de las imposiciones neoliberales, que quisieran desmantelarlo, han heredado ciertos derechos y obligaciones para sustentarlo, no sin descalabros. Al contrario, el Estado desarrollista — que imita al benefactor, pero se queda corto debido a que su función ha quedado constreñida a gestionar el subdesarrollo-, ha prohijado un proletariado precarizado y, dada esa generalización descendente, la diferenciación al seno de la clase trabajadora no ha sido tan marcada como en las economías centrales. Por lo anterior, es comprensible que en la era del capital global el ascenso del proletariado precario sea un dato más marcado y disruptivo en los países desarrollados y, en cambio, no se considera una novedad en

${ }^{1}$ Para Engels (1845), los grandes sindicatos obreros forman una «aristocracia entre la clase obrera» gracias al monopolio industrial de Gran Bretaña. Lenin (1966) advierte que la aristocracia obrera es una «minoría privilegiada de obreros» frente a la "gran masa obrera», una masa de obreros aburguesados, punto de apoyo del reformismo. Esta explicación supone el divisionismo entre la clase trabajadora entre una capa privilegiada de trabajadores frente a la gran masa, donde están, por ejemplo, los inmigrantes en las peores condiciones, y del conservadurismo y reformismo del sector privilegiado. 
los países subdesarrollados, sino más bien una extensión o una profundización de la larga trayectoria de degradación laboral asociada a la carencia de derechos y la imposición del método de superexplotación. En tal sentido, la propuesta conceptual de considerar al «precariado» como una «nueva clase social» resulta descabellada en este contexto (Sotelo, 2015). En los países subdesarrollados, los trabajadores precarios del creciente sector de los servicios conforman menos un polo diferenciado de la clase trabajadora que un sector de trabajadores subsumidos a la explotación superlativa, la cual ya operaba como método estructural de extracción de plusvalor.

Conforme avanza el proceso de capitalización, con su cauda de expropiación y concentración de capitales, se reorganiza la división internacional del trabajo y se rearticula el trabajo social combinado:

Cada capitalista liquida a otros muchos. Paralelamente a esta concentración, o a la expropiación de muchos capitalistas por pocos, se desarrollan en escala cada vez más amplia la forma cooperativa del proceso laboral, la aplicación tecnológica consciente de la ciencia, la explotación colectiva planificada de la tierra, la transformación de los medios de trabajo en medios de trabajo que sólo son utilizables colectivamente, la economización de todos los medios de producción gracias a su uso como medios de producción colectivos del trabajo social combinado (Marx, 1982b:953).

\section{«Nueva burguesía»: propietarios y gestores del capital}

A la burguesía se le ha atribuido un papel revolucionario por su papel crucial en el derrocamiento del modo de producción anterior y en la gestación 
del modo de producción capitalista; por añadidura se ha reconocido el hecho de que ha fungido como la clase social que ha conducido el desarrollo de las fuerzas productivas e impulsado el desarrollo del capitalismo: «La burguesía no puede existir sin revolucionar continuamente los instrumentos de producción, esto es, las relaciones de producción, esto es, todas las relaciones sociales» (Marx y Engels, 2001:53). Empero, conforme asienta su dominio y profundiza la explotación del trabajo y de la naturaleza, ha propiciado la degradación humana y la depredación del ambiente. No en vano el capitalismo ha trastocado sus propios límites materiales y ocasionado fracturas metabólicas que ponen en predicamento no sólo el despliegue de la lógica de valorización sino la reproducción de la vida humana y del entorno planetario en su conjunto. De aquella labor lustrosa y progresista, ahora se percibe un papel opaco y conservador. En el camino, las nociones de progreso y desarrollo se nublaron y fueron cubiertas por una mácula de incredulidad o ilegitimidad. Los signos de barbarie social y crisis civilizatoria la han sustituido (Márquez, 2017).

Es bien sabido que el sistema capitalista no tiene reparos morales ni punto de reposo. Tampoco cuenta con vocación de suicida ni puede subsistir sin impulsar continuamente sus fuerzas productivas, la capacidad productiva del trabajo y los soportes tecnológicos y materiales que la posibilitan. En función de ello, estamos experimentando una reestructuración permanente del capitalismo a escala planetaria, cuya última oleada se puede remontar a los años setenta del siglo pasado y su influjo aún persiste. En el capitalismo del siglo que corre se habla de una «revolución 4.0» o, en su defecto, de una «industria 4.0» (Schwab, 2016). Tales expresiones son derivadas de los neologismos cibernéticos y aluden a las plataformas digitales que soportan la eclosión y convergencia de diversas tecnologías. 
Aunque la revolución tecnológica en ciernes no concita una revolución social automática, sí entraña recambios sociales de gran calado dentro de la trayectoria histórica del desarrollo del capitalismo, al relegar la forma de subsunción del trabajo inmediato al capital para instaurar en definitiva la subsunción del trabajo general al capital, es decir, la supeditación del trabajo científico-tecnológico, del trabajo conceptual o cognitivo, a las exigencias del gran capital y su implantación como mecanismos dominantes en la organización de las dinámicas de valorización. La actualización de procesos, materiales, instrumentos y productos está soportada por la innovación y la ciencia aplicada; los procesos intensivos en trabajo vivo ceden su lugar a procesos intensivos en trabajo muerto; la ciencia se convierte en apéndice del capital y en consecuencia se destruyen capitales obsoletos y fuentes de trabajo, a la vez que emergen y se despliegan nuevas formas de trabajo.

Bajo esas premisas, el capital extiende sus dominios en todos los confines del planeta. La lógica inexorable de valorización se ha trasminado en prácticamente la totalidad de espacios de producción, desde la agricultura, la agroindustria y la industria, hasta los servicios, pero también de la industria de servicios y los servicios industriales. Pese a contar con una nueva base tecnológica y un trabajo potenciado en grado superlativo, todavía los espacios de valorización global no pueden prescindir del trabajo vivo, la energía vital del capitalismo. Al contrario de la tesis que dictamina la extinción del trabajo, el capitalismo aún precisa de ampliar el espectro laboral y en consecuencia el fenómeno de la proletarización de la humanidad sigue inmarcesible. No obstante, en ese movimiento expansivo también se reconoce la impronta de la diferenciación, segmentación, descentralización y heterogeneidad de las clases trabajadoras. 
Con el despliegue del capital global acontece un doble movimiento en el cuadro de las clases principales del capitalismo: destacadamente la emergencia de una «nueva burguesía» y de un «nuevo proletariado».

Los grandes capitales son amasados por propietarios que ya no son precisamente los grupos familiares y herederos de dinastías, sino que están compuestos por grupos de accionistas, donde las grandes corporaciones son sociedades anónimas; tema abordado por Marx donde considera que las empresas capitalistas por acciones, como las fábricas cooperativas, son formas de transición del capitalismo al socialismo (1982a). La función de propiedad por acciones sigue siendo rentista y parasitaria, pero los intereses de la burguesía globalizada demandan de ejércitos de funcionarios que gestionen la expansión de los grandes capitales en el ámbito internacional. Para su despliegue operativo y mejor funcionamiento, las grandes corporaciones multinacionales requieren de la formación de una gran burocracia que realice la función de gestión de los intereses del capital global, la cual incluye a cuerpos profesionales de los Estados en la esfera supranacional donde cohabitan la tecnocracia de los organismos internacionales y los cuerpos político-diplomáticos de los gobiernos. La gestión empresarial la realizan los equipos directivos y gerenciales adscritos directamente a los grandes consorcios, en consonancia con grupos empresariales que fungen como proveedores. Como estructuras paralelas de acompañamiento se reproduce una multiplicidad de organizaciones de la sociedad civil que aparece bajo la figura de fundaciones, organizaciones no gubernamentales, cabilderos y consultores, que establece vínculos de colaboración con instituciones y grupos sociales en los países donde se asientan los grandes capitales que expanden una vertiginosa red de intereses corporativos dentro del tejido societal. 
Una «nueva burguesía» parece florecer a partir de la separación aparente entre propietarios y gestores del capital global. Aunado a la burguesía, la clase propietaria de los medios de producción emerge airosa la figura de los gestores y administradores, que asumen un papel preponderante en el despliegue del capital global. A comienzos del capitalismo, los gestores estaban divididos por sectores y al interior de ellos fragmentados en diversas instituciones y unidades económicas, sin que establecieran vínculos entre sí (Bernardo, 2009:283).

Por una parte, en todos aquellos trabajos en los cuales cooperan muchos individuos, la cohesión y unidad del proceso se representan necesariamente en una voluntad dirigente, y en funciones que no sólo afectan a las labores parciales sino a la actividad global de ese lugar de trabajo, como es el caso del director de una orquesta. Este es un trabajo productivo, que debe efectuarse en cualquier modo de producción combinado.

Por otra parte $-\mathrm{y}$ con total prescindencia del sector comercial—, este trabajo de supervisión se origina necesariamente en todos los modos de producción que se basan en el antagonismo entre el trabajador, en cuanto productor directo, y el propietario de los medios de producción. Cuanto mayor sea este antagonismo, tanto mayor será el papel que desempeña este trabajo de supervisión (Marx, 1982a:490-491).

El trabajo de dirección y supervisión, en la medida en que no es una función especial que surja de la naturaleza de todo trabajo social combinado, sino del antagonismo entre el propietario de los medios de producción y el propietario de la mera fuerza de trabajo (...), esta función originada en la servidumbre del productor directo se ha convertido, con suma frecuencia, en argumento justificativo de esta misma situación, y la explotación, la 
apropiación de trabajo impago se ha presentado con igual frecuencia como el salario correspondiente al propietario del capital (Marx, 1982a:493).

Con el desarrollo del capitalismo, los gestores se fueron desprendiendo de la función productiva en el seno de las empresas y se configuraron como un sector especializado y relativamente autonomizado. Máxime con el programa neoliberal, los gestores adquieren un papel relevante en el despliegue del capital global. Cada vez más, las altas burocracias privadas y públicas toman las grandes decisiones. Los viejos y nuevos gestores del capital asumen el control estratégico del capital colectivo mundial que funciona de manera articulada a escala global. Su preponderancia es tal, que se apropian de grandes parcelas del plusvalor global creado por los trabajadores y las dividen con los propietarios, al grado que puede confundirse a unos y otros.

En las altas esferas del gran capital, el burgués clásico, el capitalista que dirige directamente una empresa se difumina y adquiere la fisonomía de un capitalista abstracto que vive de las ganancias y rentas que le reportan sus empresas, las cuales son gestionadas por los denominados directores ejecutivos de la empresa (chief executive officer [CEO]), que asumen la función de la gestión o dirección administrativa de una empresa. Esta capa directiva empresarial de alto nivel está formada en las universidades privadas globales en áreas como economía, administración o mercadotecnia. Son doctos en el diseño de programas de reestructuración corporativa que incluyen ajustes laborales, es decir, despidos de trabajadores. Estos gestores empresariales son, al final de cuentas, trabajadores asalariados, configuran la crema y nata de la moderna aristocracia obrera que participa de las superganancias de los grandes capitales monopolistas, y eventualmente 
participa en los paquetes accionarios de las corporaciones. Este fenómeno había sido abordado por Marx y Engels en sus primeras manifestaciones, pero en el capitalismo contemporáneo cobra singular importancia en el desdoblamiento de las funciones de propiedad y gestión del gran capital ubicado en la punta de la cresta del fenómeno de reproducción ampliada del capital a gran escala.

Los gestores del capital global se encargan de tejer las redes de valorización a escala global para el capital productivo, extractivo, industrial, comercial, financiero y rentista. Ejércitos de cabilderos, consultores y abogados pactan condiciones legales, laborales, territoriales e infraestructurales con los gobiernos de los Estados receptores para la instalación de las grandes inversiones: plantas industriales, megaminería, yacimientos petrolíferos, monocultivos, gran turismo, etcétera. Asimismo, los gestores del capital se encargan de operar grandes fondos de inversión y orientarlos hacia paraísos fiscales con objeto de evadir impuestos y lavar dinero de origen ilícito. Tienen la capacidad técnica de diseñar e implementar esquemas de «contabilidad creativa» elusiva del fisco, empresas extraterritoriales (offshore) y banca en la sombra (shadow banking). En tal caso, las formas del capital ficticio analizadas por Marx (1982a), a saber, el dinero crediticio, los bonos gubernamentales y las acciones, en la actualidad toman formas más sofisticadas en los instrumentos financieros derivados (un contrato que representa una promesa de pago sobre un activo subyacente futuro) y la banca en la sombra (operaciones crediticias opacas o desreguladas).

Un caso peculiar es la gestión financiera de las pensiones —el salario diferido- que convierte los ahorros de los trabajadores en un instrumento de especulación financiera. Los fondos de pensiones — que representan alrededor de 70\% del capital financiero global— concentran recursos 
de los trabajadores, quienes formalmente son propietarios, para que sean operados por los gestores financieros, los cuales toman las decisiones de inversión con esos recursos salariales y cobran onerosas comisiones, sin asumir riesgos por quebrantos derivados de los altibajos en los mercados financieros o debido a malas decisiones de inversión. Esta forma de gestión no sólo desnaturaliza el fondo de vida obrero, un recurso salarial transmutado en capital, sino que se convierte en un mero instrumento de especulación financiera que, a menudo, termina por asumir otra forma de expropiación de los fondos salariales por el capital financiero.

Entre los esquemas de negocio, también se incluyen los proyectos de inversión del capital social fijo o de infraestructura mediante los esquemas de asociación público-privada (APP): la forma trinitaria de la gestión estatal del desarrollo capitalista mediante los adelantos de capital en forma de medios colectivos de producción y medios colectivos de consumo, sin contar los servicios legislativos, judiciales y del orden público; el capital corporativo con sus negocios y emprendimientos productivos y especulativos; y el trabajo subsumido a la avanzada capitalista y sujeto al despojo de medios de producción y de vida, incluyendo la aportación de recursos salariales diferidos (pensiones) para fines especulativos del capital financiero.

No obstante, en la esfera política, las líneas de demarcación no siempre son nítidas, inclusive pueden ocasionar conflictos al seno de la clase de propietarios capitalistas y dividirse en facciones. Asimismo, los gestores del poder político del Estado pueden establecer alianzas con determinadas facciones de la clase capitalista o pretender representar el interés del capital social en su conjunto. En otras ocasiones, inclusive, se presentarán como representantes de los intereses colectivos del capital y de los trabajadores, como sucede con los gobiernos «progresistas» o populistas. 


\section{La nueva burguesía del talento y el «cognitariado»}

La ideología burguesa en boga exalta la meritocracia, el talento, el emprendedurismo, el individualismo y el determinismo tecnológico. En ese conjunto ideocrático emerge la figura de la burguesía del talento integrada por una serie de empresarios, tecnólogos y científicos instalados en la cresta de la ola de la cuarta revolución industrial. En este caso, conviene diferenciar las funciones de propiedad, de gestión y de innovación, para evitar la confusión de considerar al llamado «talento», los científicos y tecnólogos, como la nueva burguesía, cuando en realidad son los representantes del trabajo general que se subsumen al capital, que en su órbita corporativa divide las funciones de propiedad y de gestión. A diferencia de la burguesía del talento del siglo anterior, donde las llamadas profesiones liberales (médicos, abogados, profesores) destacaban en la estructura social por sus conocimientos y función social relativamente autónoma, ahora adquieren mayor preponderancia los tecnólogos, científicos, investigadores y nuevos perfiles profesionales a partir de las ciencias, las tecnologías, las ingenierías y las matemáticas (las denominadas disciplinas STEM, por sus siglas en inglés). La ideología del «empresarialismo» estipula la formación de un «capital humano» con énfasis en el conocimiento especializado y las habilidades tecnológicas que convierten al trabajador calificado en una suerte de capital en sí mismo y sus poseedores deben funcionar como gestores de sí mismos, de ese capital que supuestamente portan o encarnan. En contraste, la «vieja» burguesía del talento experimenta cambios en su configuración: el grueso sufre una tendencia declinante por pérdida de relevancia social y se decanta hacia la proletarización, aunque algunos sectores logran pervivir en la pequeña burguesía y los mejor posicionados se insertan en la burguesía triunfante. 
Por definición, la burguesía detenta la propiedad de los medios de producción, distribución y comunicación. Con el tránsito de la subsunción del trabajo inmediato a la subsunción del trabajo general (Hinkelammert y Mora, 2001; Márquez, 2010c), cobra mayor relevancia la burguesía del talento tecnológico, es decir, los capitalistas que encabezan la revolución industrial cuaternaria amparada en la burbuja tecnocrática provista de enclaves tecnológicos, grandes laboratorios y emporios tecnológicos multinacionales. Un aspecto clave de este proceso ha sido la subsunción del trabajo general y la gestión del Estado para posibilitar la organización del trabajo científico y su aplicación al capital. La aplicación del conocimiento científico al capital permite la apropiación de un trabajo social potenciado apoyado en esquemas de protección legal, como las patentes, la propiedad intelectual y las marcas tuteladas por la nomenclatura de los organismos internacionales. Tales son las bases sociotécnicas e institucionales que permiten regentar las ganancias extraordinarias inconmensurables extensivas en el mediano y largo plazos. Aquí convergen dos grandes tendencias del capitalismo histórico, por una parte, la subsunción del trabajo general como criterio ordenador de la producción capitalista y, por otra parte, el señorío de la renta tecnológica, que desplaza a la renta de la tierra como forma preponderante de succión de una parte de plusvalor merced a los monopolios sobre un recurso invertido, es el pasaje de la tierra a la égida tecnológica. Ambos procesos son gestionados por el Estado y por esta capa de la burguesía innovadora.

El boyante «capitalismo digital» $\mathrm{o}$ «informacional» se basa en la presunción de que el capitalismo experimenta una nueva era basada en la ciencia, la tecnología y la innovación. Las plataformas, dispositivos y artilugios digitales orquestan la principal fuerza productiva del capitalismo 
contemporáneo. La meca del «nuevo capitalismo» tiene su sede principal en Silicon Valley, donde se gesta el nuevo paradigma de la innovación, el talento individual y el emprendedurismo. En esta concepción, el individualismo metodológico y la ideología neoliberal rayan en el extremo:

La mayoría de los políticos y académicos coinciden en que el espíritu emprendedor es fundamental para el desarrollo y el bienestar de la sociedad. Los emprendedores crean puestos de trabajo, conducen y le dan forma a la innovación, acelerando los cambios estructurales en la economía. Al introducir nueva competencia, contribuyen indirectamente a la productividad. El espíritu empresarial es, pues, un catalizador del crecimiento económico y la competitividad nacional (Coduras, Levie, Kelley, Sæmundsson y Schøtt, 2010:13).

El eje toral del cambio epocal parece ser la investigación, el desarrollo y la innovación (I+D+i); en tanto que la legislación internacional sobre la propiedad intelectual, sobre todo las patentes, es su principal línea de protección. Un entramado institucional genera lo que se denomina el «ecosistema de innovación» compuesto por diversos institutos de investigación, centros de transferencia tecnológica (como incubadoras de negocios tecnológicos) y centros de desarrollo en tecnología avanzada, además de programas de formación de jóvenes científicos procedentes de las STEM. Pero no se puede omitir la gestión estatal, como fuente de financiamiento y organización institucional de la innovación y la ciencia aplicada (Mazzucato, 2017), sin la cual la preponderancia de esta burguesía talentosa naufragaría.

Pero aún en los espacios emblemáticos de la innovación científica y tecnológica de la cuarta ola, debajo de la burguesía del talento subsiste una 
masa laboral precarizada. Un sector creciente de trabajadores con distintos grados de calificación y entrenamiento que tienen la habilidad de manejar el conocimiento y los programas informáticos o cibernéticos. Tienen la destreza de manejar el conocimiento procedimental técnico y administrativo (know how) que sirve de soporte, cada vez más, a distintas esferas de la producción, las finanzas, el mercado y el Estado. No obstante, como sucede con otras categorías de trabajadores calificados y no calificados, también enfrentan condiciones laborales precarias. Algunos autores se han referido a este sector de trabajadores como el «cognitariado» (Boutang, 2004; Berardi, 2003; Srnicek, 2018), como una extensión del «precariado», una presunta nueva clase social ubicada en los servicios poco calificados, pero en este caso se refiere a un sector laboral muy calificado que sustenta la burbuja de alta tecnología bajo el auspicio de una supuesta «producción inmaterial».

En Silicon Valley, donde tienen su sede empresas del «capitalismo cognitivo» como Facebook, Apple, eBay, Google, Netflix y otras (FAANGM), en el subsuelo de ese «ecosistema» perviven muchos trabajadores de rango medio, como ingenieros que pueden percibir altos salarios, pero tienen gastos onerosos tan sólo para pagar el alquiler por lo que apenas libran el mes o los trabajadores de menor rango que perciben bajos salarios y no alcanzan a pagar el alquiler de un departamento o cuarto. Sin mencionar el hecho de que en las inmediaciones de este polo tecnológico viven familias pobres, incluso en la calle o en autos, incluyendo inmigrantes mexicanos que se dedican a labores de limpieza en esas empresas.

Asociada a la división internacional del trabajo y el conocimiento, la «maquila tecnológica» $\mathrm{o}$ «maquila inteligente» consiste en esquemas de producción que emplean tecnologías medias y altas en las que se pueden usar procesos automatizados con robótica, inteligencia artificial, pero también 
determinados procesos intensivos en fuerza de trabajo. ${ }^{2}$ Se elaboran o ensamblan partes y piezas de equipos electrónicos, insumos para aeronáutica espacial, insumos para equipos médicos, insumos para la industria del cine y televisión. También el proceso de ensamble de productos terminados como los automóviles. En segmentos más elaborados, laboratorios, centros de investigación, que operan bajo contrato de grandes corporaciones para el desarrollo de productos, patentes... La producción de la maquila contiene actividades que se «fragmentan» y se dispersan geográficamente, acorde a estrategias transnacionales de maximización de ganancia y reducción de riesgos, lo cual implica un rediseño de la producción (cadenas globales de producción y servicio), y de la estructura y función del comercio (comercio intrafirma).

En la inserción a las cadenas globales de valor, los países subdesarrollados se reconvierten en plataformas de exportación operadas por los capitales multinacionales que aprovechan los bajos costos de la fuerza de trabajo y todas las facilidades, apoyos y exenciones estatales.

La mayor parte de la tecnología incorporada por las grandes corporaciones se trata de equipo, insumos, diseño y dirección provenientes de los países centrales, que representan erogaciones por concepto de renta tecnológica, tal es el caso del pago de patentes. Una novedad es que en los países periféricos se está produciendo tecnología, pero bajo una modalidad de

${ }^{2}$ La llamada «maquila inteligente» ha mostrado una gran capacidad de renovación tecnológica. Por ejemplo, la maquila de equipos electrónicos que en principio se especializaba en el ensamblaje de microprocesadores de 65 y 99 nanómetros, se adapta para fragmentar la actividad de producción de los microprocesadores de tecnología alta de 22 nanómetros y pueden cambiar a la producción de los microprocesadores de 10 nanómetros, la tecnología comercial más avanzada y cuya actividad de producción también está siendo «segregada» de los eslabones centros de la cadena. Pero no sólo se trata de una fábrica de manufacturas, sino de servicios globales en finanzas e ingeniería. 
«maquila tecnológica», que significa la explotación del trabajo altamente calificado por corporaciones extranjeras. Salvo contados casos, como Brasil o India, no existe una generación endógena de ciencia y tecnología vinculada a un proyecto de desarrollo nacional (Márquez, 2012:14).

\section{Lumpenburguesía}

Si existe alguna duda o controversia sobre el papel progresista de la burguesía en la actualidad, no existe, en contraste, reparo alguno de que determinadas capas de la burguesía no realizan ningún papel positivo en la economía y la sociedad, pues aunado al hecho de que se apropian del trabajo ajeno y acumulan riqueza de manera desproporcionada, lo hacen con métodos descaradamente nocivos y obscenos, como la violencia, la corrupción, el hurto, el tráfico de influencias, la especulación. Atributos de los que no está exenta, por cierto, el resto de la burguesía, desde la más reputada y ostentosa, hasta las capas más moralistas y puritanas. Pero en este caso se trata de un modo de vida, una forma inmunda de moverse en las sombras, en la ilegalidad y la impunidad, con la astucia de que pueden salir también a la luz, hacer negocios legales y codearse con los poderes económicos y políticos, incluso fungir como benefactores de la sociedad.

En los escalones bajos de la burguesía perviven formas contrahechas, degradadas y espurias de la burguesía. En los márgenes del Estado nación, apoltronada en nichos protegidos por el Estado, persiste la forma 
horrenda de lumpenburguesía, ${ }^{3}$ que se subdivide en dos categorías: por una parte, las supuestas burguesías nacionales subordinadas a las burguesías multinacionales que cumplen papeles subsidiarios, como rentistas o proveedores, pero que en realidad fungen como correas de transmisión en los mecanismos de transferencia de valor a escala mundial, donde pueden alternativamente asumir posturas nacionalistas, pero también internacionalistas, según sus intereses; por otra parte, está la burguesía criminal que se mueve entre lo legal y lo ilegal, lo formal y lo informal, en torno a formas de capital criminal, corrupción, tráfico de influencias e impunidad.

\section{La moderna clase media o la pequeña burguesía}

El trabajo de la llamada «clase media» alude, sobre todo, a uno de tipo intelectual, empresario o falso trabajador libre, que está investido de una ideología de corte individualista que insufla a este sector de ilusiones y aspiraciones maximalistas, emparentadas con los valores burgueses, cuando en realidad está montada sobre arenas movedizas que reiteradamente la hunden y sumergen en la degradación social.

La ideología del «emprendedurismo» se ha inoculado entre los trabajadores que no quieren ser asalariados y añoran tener su propio negocio, ser empresarios, un pequeño patrón o cuando menos el «patrón de sí mismo», cuando la mayoría de las veces se convierten en un «obrero de sí mismo»

${ }^{3}$ Frank (1973) denominaba lumpenburguesía para referirse a la burguesía de los países subdesarrollados, como en América Latina, que al desempeñar su función como industriales, comerciantes y otras actividades afines, tienen una capacidad productiva endeble, no disponen de conciencia política y están supeditados a sus contrapartes de los países centrales. 
que explota su propio trabajo y de manera ampliada el trabajo de sus familiares. Una gran porción de quienes emprenden este derrotero sucumbe pronto, quiebran porque no pueden afrontar la competencia.

Así como en el siglo XIX se gestó un proletariado industrial y en el siglo XX se expandió el proletariado rural, en el actual tiene verificativo un desclasamiento de la clase media y la procreación de un vasto proletariado en los servicios. Ha ocurrido una reconversión en los mercados laborales, pues los sectores estables, que eran predominantes, se convierten en excepcionales, y la preponderancia la toman los sectores laborales precarios, compuestos por la figura del trabajo temporal, parcial y terciarizado. El trabajo reglamentado con base en derechos y seguridad laboral, que era más o menos la regla, se convierte ahora en la excepción. De manera particular, este proceso reciente tiene como plataforma de lanzamiento el mundo digital, la expansión del capital financiero y los ajustes espacio-temporales propios de la composición de redes de capital global. La reconfiguración del capital ha modificado la morfología de las empresas industriales, agrícolas y los servicios. Al igual que una fábrica, agroindustria o empresa de servicios ha sido rediseñada espacial, tecnológica y productivamente, el proletariado ha sufrido importantes modificaciones en su formación, ahora adquiere un perfil laboral más joven que opera máquinas digitalizadas, las cuales pueden requerir el manejo básico de algún idioma extranjero — p. ej., inglés - y determinados conocimientos técnicos básicos, pero al mismo tiempo es una fuerza laboral crecientemente despolitizada, desorganizada, inmediatista, maleable y móvil. 


\section{Formación de un proletariado internacional}

En el capitalismo mundial, las clases sociales representan a los sujetos históricos que tejen alianzas y despliegan confrontaciones para hacer posible el despliegue de la lógica de valorización del valor con todas sus contradicciones a cuestas. La relación desigual entre capital y trabajo, entre burguesía y proletariado, sigue marcando la pauta en la configuración social de las formaciones sociales capitalistas, hacia adentro y hacia afuera, si consideramos la trama de la división internacional del trabajo, el mercado mundial y las formas de desarrollo desigual. Estos factores se articulan y dan lugar, en la práctica, a disímiles tasas de explotación, diversos montos de trabajo excedentario extraído, la configuración de la estructura de precios y la expansión planetaria del mercado, espacio superpuesto donde se redistribuye el plusvalor, y el salario se ajusta a una media global pero se diferencia drásticamente en los ámbitos regionales y nacionales, se determina las rentas de las clases no capitalistas y se entremezclan los intercambios entre centro-periferia, los flujos de mercancías y de capitales, con sus tasas de cambio, entre otros flujos y movimientos de capital y trabajo.

En el trasfondo de esta maraña mercantil global, subyace el trabajo productivo y las clases trabajadoras que lo hacen posible, lo generan a costa de su propia explotación. Para que ello sea posible, permanentemente se tiene que estar recreando camadas de trabajadores dispuestos a ingresar a los mercados laborales segmentados en sectores y regiones, y muy diferenciados en escalas salariales. El trabajo se torna múltiple, heterogéneo, pero coordinado socialmente por el capital. Es propio del capitalismo operar con el trabajo social combinado: 


\section{Morfología del tRABAjo EN El CAPITALISMO GLOBAL}

Y forman la máquina productiva total participan de manera muy diferente en el proceso inmediato de la formación de mercancías, o mejor aquí de productos —éste trabaja con las manos, aquél más con la cabeza, el uno como director (manager), ingeniero (engineer), técnico, etcétera, el otro como capataz (overlooker), el de más allá como obrero manual directo e incluso como simple peón—, tenemos que más y más funciones de la capacidad de trabajo se incluyen en el concepto inmediato de trabajo productivo, y sus agentes en el concepto de trabajadores productivos, directamente explotados por el capital y subordinados en general a su proceso de valorización y de producción. Si se considera el trabajador colectivo en el que el taller consiste, su actividad combinada se realiza materialmente (materialiter) y de manera directa en un producto total que al mismo tiempo es una masa total de mercancías, y aquí es absolutamente indiferente el que la función de tal o cual trabajador, mero eslabón de este trabajo colectivo, esté más próxima o más distante del trabajo manual directo. Pero entonces la actividad de esta capacidad laboral colectiva es su consumo productivo directo por el capital, vale decir el proceso de autovalorización del capital, la producción directa de plusvalía y de ahí, como se deberá analizar más adelante, la transformación directa de la misma en capital (Marx, 1971:79).

El proceso de capitalización redunda en la consolidación y proletarización generalizada, aunada a la heterogeneidad, fragmentación y complejidad de la clase trabajadora. Al capital global le corresponde la formación de un obrero global, un proletariado internacional.

Desde los años ochenta, se ha venido configurando un nuevo proletariado internacional a disposición del capital global, una clase social compuesta, primordialmente, por trabajadores precarizados cuya reproducción 
depende de la venta de su fuerza de trabajo y que producen valor y plusvalor mediante el uso de capacidad de trabajo vivo en el marco de relaciones de producción capitalista globalizadas.

Paralelamente a esta concentración, o a la expropiación de muchos capitalistas por pocos, se desarrollan en escala cada vez más amplia la forma cooperativa del proceso laboral, la aplicación tecnológica consciente de la ciencia, la explotación colectiva planificada de la tierra, la transformación de los medios de trabajo en medio de trabajo que sólo son utilizables colectivamente, la economización de todos los medios de producción gracias a su uso como medios de producción colectivos del trabajo social, combinado (...) el entrelazamiento de todos los pueblos en la red del mercado mundial, y con ello el carácter internacional del régimen capitalista (Marx, 1982b:953).

Ya en el siglo anterior, cuando estaba en boga el régimen de gestión productiva taylorista-fordista, la composición de la clase trabajadora no era homogénea: había una mezcla de trabajadores hombres, mujeres, jóvenes, niños, ancianos; de trabajadores calificados y no calificados; de trabajadores nacionales e inmigrantes, etcétera. También se presentaba el fenómeno de la «terciarización» en actividades variadas como restaurantes, limpieza, transporte colectivo, etcétera. Sin embargo, este fenómeno se ha acentuado de forma cualitativa y cuantitativa. En el capitalismo actual, la clase trabajadora resulta cada vez más explotada, a la vez que asume una composición más heterogénea, fragmentada y diversificada por su actividad productiva, pero también destaca en ese marco la formación de un obrero polivalente que puede realizar diferentes actividades o manipular varias máquinas. Sin embargo, mayormente se trata de trabajadores 
carentes de derechos, que realizan un trabajo sin sentido, más bien acorde a la lógica destructiva del capital, cuyo metabolismo no sólo destruye la naturaleza, al borde de la catástrofe ambiental, sino que reducen a la extrema precariedad a la fuerza de trabajo, sea desempleándola, subempleándola o intensificando sus niveles de explotación.

La consolidación de la era del capitalismo global posibilita la conformación de un mercado mundial y de su concomitante clase obrera mundial, especialmente en los países subdesarrollados. Dicha tendencia impone la relación salarial en amplios conjuntos poblacionales que no estaban supeditados a esa relación de dependencia.

Acontece una expansión de los asalariados medios en sectores como el bancario, el del turismo y el de supermercados; en suma, en el llamado «sectores de servicio» en general. Se trata de los «nuevos proletarios», en términos de lo que significa su condición actual de asalariados y la degradación a la que en ese ámbito están expuestos.

\section{Incorporación del trabajo improductivo en el trabajo productivo}

El trabajo productivo — es decir, el trabajo generador de plusvalor — se encuentra subsumido realmente al capital y participa directamente en el proceso de valorización. El trabajo improductivo, al cual no se le reconoce capacidad generadora de plusvalor, ha crecido notablemente en el capitalismo contemporáneo, pese a que algunas de sus expresiones hayan decrecido o desaparecido. Como cuando una función improductiva se convierte en actividad productiva en una fábrica. De hecho, una tendencia 
del capital global es la intensificación de procesos productivos con mayor presencia de trabajo productivo y la supresión de muchas actividades improductivas. Sin embargo, no todas las funciones improductivas pueden ser eliminadas por el capital, porque muchas son importantes para que la explotación del trabajo productivo se pueda efectuar. Más aún, diversos sectores de actividad improductiva que aparentemente son eliminados, en realidad son transferidos a otras áreas de trabajo donde asumen un carácter productivo, por ejemplo la subcontratación o terciarización (outsourcing). Es un error englobar a todas las ramas de los «servicios» en el trabajo improductivo; muchos de estos trabajadores en realidad son productivos en sentido estricto, también lo son los dedicados al transporte.

Como un desmentido a la socorrida tesis del «fin del trabajo», se testifica que el capital en realidad ha amplificado los ámbitos del trabajo asalariado a escala mundial y simultáneamente ha diversificado las formas de explotación de la fuerza de trabajo mediante la precarización, el subempleo, el trabajo a tiempo parcial, y demás formas asociadas.

El modo de gestión sociotécnico toyotista ha fungido como una estrategia de intensificación del trabajo que torna a los lugares de trabajo en una insólita «fábrica de la desesperación», cuyo cometido primordial es disminuir el «desperdicio» (Kamata, 1983), es decir, el imperativo era abatir el «tiempo ocioso» en los procesos de fabricación, de manera que Toyota logró, bajo ese parámetro, reducir 33\% del desperdicio. El dispositivo ideológico convierte al trabajo enajenado en un logro personal y un sacrificio colectivo, al punto en que los trabajadores pueden sucumbir y morir debido al trabajo excesivo, como ha sido testificado en Japón, sede del toyotismo, impulsor del régimen de alto crecimiento y propagador de suicidios y enfermedades laborales (López Villafañe y Uscanga, 2015). La 
imposición del ritmo frenético de producción se hace a nombre del espíritu de la empresa, lo cual permitió a Toyota reducir en sus procesos de fabricación el «tiempo ocioso» o el «desperdicio» en 33\%. No en balde, la industria automovilística japonesa, que en 1955 producía un volumen bajo de automóviles frente a la producción estadounidense (69 mil unidades frente a 9.2 millones), alcanzó niveles de producción que le permitieron remontar la diferencia y superarla después de dos décadas de sacrificios laborales y mejoras tecnológicas. La clave ha sido acrecentar el trabajo potenciado (Marx, 1975) mediante la incesante actualización tecnológica, lo cual permite el incremento de la productividad del trabajo. En términos comparativos, unas economías otrora líderes en la producción automotriz, como la estadounidense, súbitamente presentan un escenario donde sus obreros parecieran ser incompetentes, en comparación con los japoneses, en tanto que su método de producción también se torna ralentizado, por lo que pareciera ser que los alumnos superan a los maestros, al punto en que los estadounidenses tienen que reaprender y analizar los métodos de producción japoneses. Los japoneses siempre han reconocido que aprendieron de la economía estadounidense (Coriat, 1992), por lo que el toyotismo no deviene precisamente de una invención genuina de la cultura japonesa, sino del resultado de analizar y perfeccionar modelos industriales y comerciales, para imitarlos y perfeccionarlos.

Lo que se pretende es estrechar la relación entre trabajo y valor generado, es decir, reducir al máximo posible los niveles y momentos de trabajo improductivo dentro de los procesos productivos en las fábricas de nuevo tipo, que adoptan medidas para supresión de funciones ahora consideradas redundantes, como vigilancia, inspección, supervisión, gerencia intermedia, entre otras. De lo que se trata es de desincorporar a los trabajadores 
que no realizan actividades en la creación de valor e incorporar funciones improductivas directamente en el trabajo productivo, como el modelo de gestión lean manufacturing o lean production, un método de trabajo basado en la mejora continua o el método Kaizen, y la optimización productiva mediante la eliminación de «desperdicios» y de las actividades que no suman ningún tipo de valor, para disminuir el tiempo de trabajo necesario y abatir los costos de producción (Womack, Jones y Roos, 1990).

\section{«Nuevo proletariado» en los servicios: ¿desdibujamiento del obrero fabril?}

La composición de la clase trabajadora bajo el capitalismo global, que irremediablemente vive de la venta de su fuerza de trabajo, incluye diversos segmentos, desde los que se adhieren a la forma industrial y el trabajo asalariado en un perfil más «clásico» hasta el «nuevo proletariado» con otros perfiles laborales en actividades de servicios, como subempleados, trabajadores precarios, algunos de los cuales pudieran parecer fuera de lugar. A su vez, la complejidad de la clase trabajadora pudiera parecer mayor si se considera que históricamente ha estado entrecruzada por otras determinaciones internas, como las diferencias de género, raza y nacionalidad, los inmigrantes y los nativos, las cohortes generacionales, los niveles de calificación y otras.

Al modificarse las estructuras productivas y laborales a escala mundial, ocurre un desgarramiento del tejido social en los países y comunidades para dar lugar a una metamorfosis de la cuestión social en el capitalismo actual. En tal sentido, destaca la emergencia del nuevo y desbordante 
proletariado de los servicios como un segmento diferente a otros que también integran la clase trabajadora.

En El capital, Marx había demostrado que la precarización es concomitante al trabajo asalariado. Conforme la clase trabajadora se ve compelida a vender su fuerza de trabajo y por ello sólo recibe un pago por una parte del valor producido - el salario-, el excedente resultante, el trabajo impago o plusvalor, tiende a expandirse mediante la intensificación del trabajo, la extensión de la jornada laboral y la restricción de los derechos de trabajadores y demás. La precarización redoblada del trabajo se debe a la lucha de clases, que como tal puede ampliarse o reducirse dependiendo de la correlación de fuerzas entre el capital y el trabajo. Con la crisis estructural del capitalismo global se desencadenó un proceso amplio de precarización del trabajo, que ya se venía implementando con el acusado proceso de neoliberalización (Mészáros, 2010; Márquez, 2010a).

A grandes pinceladas, acontece un doble movimiento: la reducción del trabajo estable y la amplificación del trabajo precario. El primer movimiento alude a la disminución relativa del proletariado manual, fabril y estable, que fuera típico de la fase taylorista y fordista. Este perfil de proletariado se ha reducido en términos relativos en el nivel mundial, aunque con diferentes grados dependiendo de cada país, sea desarrollado o subdesarrollado, y del papel en la división internacional del trabajo. Países que experimentaron un fuerte proceso de industrialización en los sesenta y setenta, que procrearon una gran camada de trabajadores manufactureros, en las últimas décadas han experimentado un descenso en los trabajadores del sector. En gran medida, debido a que una misma fábrica produce ahora más con menos obreros, merced al progreso tecnológico, lo cual pudiera presagiar la supuesta extinción del proletariado; sin embargo, hay 
otras tendencias que advierten cómo se ha diversificado el mundo del trabajo y ampliado la cuantía de trabajadores. En contraste con el descenso relativo de los obreros fabriles, ocurre un aumento espectacular a escala mundial de la masa de trabajadores asalariados y del proletariado precario. De lo cual se deduce el siguiente movimiento, con la flexibilización y desregulación del trabajo que ha insuflado el fenómeno de la «terciarización», que tiende a generalizarse en actividades que sirven a otras o en aquellas que se convierten en un fin en sí mismo. Conforme los empleos estables disminuyen, aumentan los empleos a tiempo parcial, trabajos temporales. La expansión de los asalariados de los servicios se registra en una miríada de actividades, como el reparto a domicilio, el cuidado de personas, atención a clientes en tiendas, vendedores ambulantes, entre muchas más.

La recomposición del obrero fabril en los centros con ampliación en las periferias debido a redes de capital global: en los países desarrollados, los trabajadores más precarios, incluyendo a jóvenes, inmigrantes, afrodescendientes, entre otros, conforman este segmento provisto con derechos menguantes, y que tiene que estar luchando para adquirir y preservar derechos mínimos. En tanto que los segmentos más tradicionales de la clase trabajadora, herederos de los vestigios del sindicalismo y el Estado de bienestar o su remedo, tienen que luchar para defender los derechos adquiridos y proteger sus condiciones laborales de la ofensiva de la precarización desbocada.

El desclasamiento de la «clase media» o la proletarización de la pequeña burguesía es un fenómeno de grandes proporciones. Los servicios se han expandido en el capitalismo actual mediante la proliferación del «nuevo proletariado» que, de entrada, degrada las formas anteriores de prestación de servicios profesionales de las capas medias decimonónicas 
con dotes de trabajo intelectual, como eran los profesionistas liberales (médicos, abogados, etcétera). La proletarización de las capas medias supone procesos más intrincados que los que fueron caracterizados en su momento por Braverman (1984), en la medida en que este nuevo proletariado se masifica y diversifica en actividades asociadas a nuevas tecnologías, redes de capital global y venta de mercancías de consumo instantáneo, como se desprende de un conjunto amorfo de actividades expansivas: centros de llamadas (call center), hoteles, supermercados, cadenas de comida rápida, minoristas de gran escala y muchas más. Por su heterogeneidad estructural, los segmentos altos de la llamada clase media, con mayores ingresos, educación y relaciones, esgrimen una serie de valores, ideología, cultura, símbolos y patrones de consumo que buscan identificarse con las clases propietarias, como sucede con los gerentes, administradores, ingenieros, médicos y abogados de nivel medio a superior. Al contrario, los estratos bajos ostentan niveles de vida similares a los de las clases trabajadoras y tienden a identificarse con ellas, como sucede con los empleados de servicios, involucrados más directa o indirectamente con los procesos de valorización de capital. Diversos trabajadores asalariados de sectores laborales dinámicos, como la mercadotecnia, comercio minorista, servicios de alimento, etcétera, se están acercando al nuevo proletariado.

No forman parte de la supuesta clase media ni forman una nueva clase social. Standing (2013) plantea que el «precariado» es una nueva clase social diferente al proletariado emanado de la revolución industrial y consolidado en la etapa taylorista-fordista; desde esa perspectiva ahora se trataría de una «nueva clase» desorganizada, ideológicamente dispersa y atraída por políticas populistas, incluyendo neofascistas, y en tal caso la tilda de «peligrosa». La tendencia es hacia la flexibilización del trabajo, sin días de 
trabajo preestablecidos, sin espacios de trabajo definidos, sin salarios fijos, sin actividades predeterminadas, sin derechos y sin protección ni representación sindical. La productividad por objetivos es flexible, puesto que se busca que los logros actuales sean superados el día de mañana.

\section{Terciarización: abultamiento del trabajo en los servicios}

En las últimas décadas, la «terciarización» ha fungido como palanca central para la extracción de plusvalor y la obtención de ganancias a nivel exponencial. En empresas públicas y privadas los servicios de limpieza y de seguridad estaban a cargo de trabajadores de la misma empresa; pero con la subcontratación, una empresa terciarizada ofrece trabajadores que cubren esas funciones vacantes en el área de seguridad o en el área de limpieza. Estos trabajadores subcontratados no cobran en las empresas donde realizan su función, lo hacen en las empresas subcontratistas, que son contratadas por las empresas públicas o privadas y pagan a sus trabajadores. Ese mecanismo se hace extensivo a una amplia gama de actividades que antes prestaban trabajo sin fines de lucro, en el caso del sector público, o eran trabajadores de familia, como médicos o abogados de familia. Ahora existe una masa de abogados o médicos jóvenes desempleados, que son «empleados» por diversos despachos, consultorios u hospitales según sea el caso, donde inician su carrera atendiendo a varios convenios, bajo una racionalidad privatizadora en pos de ganancia y valorización del capital. Bajo esa lógica operan la telemercadotecnia (telemarketing), la informática, las comunicaciones, la hotelería, las cadenas de comida rápida (fast food) y los motociclistas repartidores. 
El nuevo perfil del proletariado de servicios dibuja un contorno laboral donde se trabajan más horas, con ritmos más intensos, alta rotación y salarios reducidos, con inseguridad, mala salud y mínimas protecciones regulatorias.

El trabajo subcontratado responde a una estrategia corporativa para aminorar costos laborales y desprenderse de actividades que serán recontratadas a empresas de servicios que a su vez contratan trabajadores en las peores condiciones para que realicen esas labores, con lo cual se perfila un trabajador subcontratado desprovisto de derechos y con trabajos volátiles. Cuando una empresa requiere, por ejemplo, servicios de seguridad y limpieza o cuando un consumidor domiciliario requiere un servicio de telefonía, internet, televisión o electricidad, quienes acuden a la empresa o al domicilio son el personal subcontratado que no suelen ser empleados de la compañía que provee el servicio, por tanto se trata de trabajadores terciarizados o autónomos terciarizados que son subcontratados por una empresa que presta ese tipo de servicios, es decir, el trabajador es contratado, hace el servicio y cobra sólo por el servicio que hace en la casa o empresa donde es llamado. Ese mecanismo operativo se multiplica en otras modalidades de prestación de servicios. Al agrupar el cúmulo de trabajos subcontratados con el trabajo intermitente, podemos apreciar que se ha creado una miríada de trabajos precarizados.

Un ejemplo peculiar son las «maquiladoras», los modernos talleres del trabajo esclavo, que no son plantas industriales integrales sino formas de servicios industriales subcontratados intensivos en trabajo barato, sobre todo femenil, que basan su esquema operativo en la determinación de bajar al extremo el precio de los costos de producción dentro de una extendida cadena de suministros globalizada. En estos eslabones productivos se 
acrecientan los márgenes de ganancia mediante la superexplotación del trabajo y la venta masiva de mercancías a bajo precio, como ocurre con los textiles y el calzado, o mediante la fijación de precios de monopolio, como en los automóviles, aeronaves y aparatos electrónicos.

El trabajo intermitente prolifera en los mercados laborales degradados con una tendencia acusada hacia la expansión global y que se basan en esquemas de trabajo por tiempo determinado y contratos flexibles o sin ellos, pues habitualmente operan a expensas de los marcos legales que pudieran establecer cláusulas de protección a los trabajadores.

Las formas de profundización de la explotación laboral son múltiples, y algunas de ellas parecieran disfrazarla al presentar a los trabajadores como agentes independientes, incluso resueltamente ya como empresarios, pero en realidad se trata de modalidades variopintas de trabajo informal, a tiempo parcial, temporal, independiente, ocasional e intermitente.

La expansión global del turismo se convirtió en una palanca de acumulación de capital a escala mundial, inclusive varios países tienen al turismo como su primera o una de sus principales fuentes de riqueza. Como sustento de este sector, se ha engendrado un nuevo proletariado abocado a la industria turística. Ejemplo de ello son las camareras de piso, que disponen de un tiempo medido para hacer la cama en un cuarto de hotel y cuando ellas logran reducir 40 o 50 segundos o un minuto o minuto y medio la hechura de una cama, al final del día arreglarán varios cuartos más por el tiempo que ganaron. El sector de la comida rápida, que está esparcido por el mundo entero, está sustentado en el nuevo proletariado de servicios. De igual modo, el uso masivo de telefonía celular ha propiciado la explosión de los centros de llamadas donde labora personal con características similares. La nueva constelación de servicios globales ha generado 
una gran masa de trabajadores, el proletariado de los servicios, como otrora fuera la masa de asalariados del sector público que alimentaba la burocracia y los servicios públicos.

No obstante, en los multifacéticos sectores laborales intensivos en fuerza de trabajo de la economía de servicios, como los centros de llamadas, las cadenas de comida rápida, las cadenas de hotelería y comercio, el proletariado suele no considerarse como tal. Esta crisis de identidad proletaria ocurre, paradójicamente, mientras se abaten los tiempos de circulación de las mercancías, se incrementa el tiempo de trabajo y de traslado de los nuevos proletarios, o se amplía el tiempo de trabajo efectivo con modalidades de trabajo en casa o el teletrabajo. Además, los trabajadores tienen que pagar transporte urbano, tomar un tiempo de traslado de dos o más horas para ir de las zonas periféricas de la ciudad donde residen a los distantes lugares de trabajo, de igual forma que lo hace un obrero fabril. Antes y después de trabajar, sus horarios son amplios, pues tendrán que salir con suficiente anticipación, dos o tres horas antes de comenzar su jornada de trabajo y otro tanto para salir y retornar al hogar, por lo que en términos redondos pueden destinar unas 12 horas o más para cumplir con su trabajo, eso si tienen una jornada de ocho horas, porque pudiera ser mayor, sobre todo cuando cubren horas extras. Eso sin contar el hecho de que pueden tener más de un trabajo. Pero también puede ocurrir lo contrario, siendo trabajadores intermitentes pueden ser llamados para ocupar una labor que puede ser de pocas horas y otra labor en ese mismo día también de un tramo corto, por lo que no podrá regresar a casa a fin de cumplir los llamados del día, si es que son requeridos.

En lugar de que los avances tecnológicos provistos por la inteligencia artificial, la robótica, etcétera cristalicen el ideal del tiempo libre, del «reino de 
la libertad» (Marx, 1988:1044; Engels, 2003), donde un trabajador en la mañana pueda dedicar unas cuantas horas al trabajo productivo, más tarde cultivar una disciplina artística, después hacer deporte, posteriormente apreciar un acto cultural y al caer la tarde filosofar, la realidad es que para millones de trabajadores en el mundo la jornada laboral se amplía o se estrecha, pero sin posibilidades de subsistir dignamente y mucho menos de desplegar sus potencialidades críticas y creativas. Por ejemplo, los trabajadores jóvenes pueden durante una parte del día laborar en una fábrica, una escuela o una oficina, en la tarde desempeñar otro trabajo en algún servicio, un oficio o la venta de alguna mercancía y si es necesario pueden tener hasta un tercer trabajo para poder ampliar sus ingresos que le permitan apenas sobrevivir. Esta condición también suele presentarse en la esfera del trabajador calificado derivado de la tendencia hacia la descalificación laboral, hecho que por ejemplo se presenta en la proletarización de los trabajadores intelectuales, como los profesores, o en oficinas donde proliferan contadores y abogados o consultorios médicos que contratan profesionistas temporalmente o para un proyecto específico, según sea el caso. El trabajo desregulado se está globalizando y atraviesa los distintos niveles de calificación laboral, en tanto que los marcos de protección legal se están constriñendo y desfasando de la realidad y a lo sumo experimentan pequeñas adecuaciones, siempre que se expresen grandes fuerzas sociopolíticas de resistencia y lucha.

La figura del «subproletariado» es funcional a las estadísticas oficiales para recubrir el desempleo galopante y para ocultar una realidad social lacerante, en la medida en que el trabajador intermitente es clasificado como empleado, cuando en la realidad a menudo este tipo de trabajador se encuentra en la reserva, indefinidamente, a la espera de recibir el llamado para trabajar, en consecuencia representa una forma de desempleado disfrazado. 
En tanto que el trabajador precarizado y subempleado no es derechohabiente de la seguridad social y no tiene la capacidad de pagar un seguro médico privado, este tipo de trabajador informal vive en carne propia el deterioro de su salud, la expectativa de un envejecimiento carente de derechos y la imposibilidad de asumir los costos hospitalarios en caso de enfermedades crónicas, degenerativas o accidentes. En lo inmediato, la ilusión de ser «independiente» $\mathrm{y}$ «empresario», sin aparente sujeción al mando corporativo, contrasta con la cruda realidad de la pérdida de derechos sociales y laborales, aunado a la insolvencia para afrontar problemas de salud y un retiro digno.

Algunos sectores laborales no cuentan con derechos, están sujetos al despido, pero detentan altos salarios, como los periodistas mediáticos, los artistas y deportistas, además de que se mueven en círculos sociales elitistas donde tejen relaciones de poder y se posicionan en el centro del espectro cultural y los espectáculos. Sus altos ingresos, que más que una forma salarial, devienen del hecho de participar en la distribución del plusvalor, les permiten acceder a sistemas de salud privados, invertir en acciones y empresas, disfrutar de un estilo de vida lujoso y derrochador, cuya imagen suele utilizarse como ejemplo del éxito y el poder. En contraste, los gestores del capital que se desempeñaban en puestos directivos, gerenciales o mandos medios que fueron desprendidos del organigrama empresarial, por políticas de ajuste, edad o reestructuración corporativa, y pese a su experiencia y años de servicio, no logran fácilmente conseguir un empleo en puestos semejantes a los que desempeñaban. Más aún, en la base de la pirámide salarial, se ubican trabajadores que mediante argucias verbales son clasificados falsamente como «gestores», «gerentes» o «asociados» en las empresas, a fin de encubrir su condición de trabajadores asalariados; en 
realidad no son gerentes ni ejercen ninguna función de mando sobre otros trabajadores, sino que apenas se mandan a sí mismos, como habitualmente ocurre en empresas comerciales, por ejemplo en los supermercados, como es el caso del gerente de ventas al por menor.

\section{Cambios sociotécnicos y gestión del trabajo: intensidad fabril generalizada (tiempos, movimientos, espacios)}

La subsunción del trabajo en el capital, el desarrollo de las fuerzas productivas y la aplicación de la ciencia en la producción han sido una constante en el modo de producción capitalista:

En la subsunción real del trabajo en el capital hacen su aparición en el proceso de trabajo todos los changes que analizamos anteriormente. Se desarrollan las fuerzas productivas sociales del trabajo y merced al trabajo en gran escala, se llega a la aplicación de la ciencia y la maquinaria a la producción inmediata. Por una parte el modo capitalista de producción, que ahora se estructura como un modo de producción sui géneris, origina una forma modificada de la producción material. Por otra parte, esa modificación de la forma material constituye la base para el desarrollo de la relación capitalista, cuya forma adecuada corresponde, en consecuencia, a determinado grado de desarrollo alcanzado por las fuerzas productivas del trabajo (Marx, 1985:73).

En las etapas más recientes, en contraste con el taylorismo y el fordismo, todavía vigentes en diversas partes del mundo y en formas combinadas que el término «posfordismo» quisiera obnubilar, el toyotismo convierte al 
trabajador en un ser completamente enajenado, un severo administrador o controlador de sí mismo, hasta grados que rayan en el despotismo. En un afán de mistificación del capital, el trabajador asume la responsabilidad de que su producción alcance el estándar de la «calidad total», y de no lograrlo puede asumir actitudes de autoflagelación o recriminarse a sí mismo por su descalabro. El trabajo se organiza de manera colectiva, mediante equipos o grupos de trabajo, que vigilan, por ejemplo, la ausencia de un compañero y consignan un castigo. El toyotismo no admite resistencias o rebeldías ante la autoridad, en todo caso se antepone el interés supremo de la empresa, toda vez que de su desempeño, se supone, se derraman los beneficios para los trabajadores, según sus cuotas de productividad. Coriat (1992) considera que el toyotismo pone en práctica tres modelos de «compromiso» del trabajador en la empresa: impuesto, incitado y negociado, formas de alienación del trabajo que gradúan la dominación corporativa del trabajo. Bajo las premisas empresariales y la «cultura laboral», la alienación del trabajo se desplaza hacia los extremos, y en el ser del trabajador se inocula una subjetividad empresarial, donde sólo tiene cabida pensar y actuar en aras de la productividad y la competitividad, para mejorar la producción de la empresa, entidad que se metamorfosea, como si fuera el propio nicho familiar o su remedo.

El trabajador se torna un agente productivo obsesionado con cumplir sus metas de productividad y establece rutinas que coadyuven a hacer un mejor uso del espacio, el tiempo y sus movimientos en el lugar de trabajo. Se puede fijar metas personales que redunden en un incremento de la productividad personal y grupal, y será el individuo mismo quien se encargue de verificar su cumplimiento.

La ideología taylorista ha propiciado un completo extrañamiento del trabajo, una pérdida de sentido, de finalidad, y, en resumen, una completa 
deshumanización del trabajo. El trabajador no es dueño de sí, sino que internaliza la función del capital, la asume como propia y termina por pensar y actuar según los requerimientos de la producción.

En vez de que irrumpa el «fin del trabajo», como suponen los teóricos marxistas que asumen la idea del derrumbe automático del capitalismo o del anacronismo del trabajo vivo por el influjo de las tecnociencias, al parejo de quienes argumentan la pérdida de fuerza estructural del trabajo abstracto, en el capitalismo realmente existente lo que se advierte es el retorno superlativo de la explotación del trabajo, mediante la mayor intensificación del tiempo y del ritmo de trabajo, incluida la desvalorización salarial. En esto caben combinaciones, por ejemplo, la jornada puede reducirse e intensificar el ritmo de trabajo, en suma, un mayor grado de explotación de la fuerza de trabajo. En contraste, en las unidades productivas de punta, aún minoritarias en la esfera laboral, ocurren formas de trabajo más «intelectualizadas» (en el sentido del capital), que algunos denominan trabajo «inmaterial». Una realidad muy diferente de la sugerida por la tesis del fin del trabajo persiste en la formación social capitalista que permite una combinación contradictoria del «trabajo social combinado», entre ámbitos del trabajo anacrónicos y otros ultramodernos. Se trataría de una peculiar imbricación entre las formas de trabajo «material» e «inmaterial», en la medida en que se acrecienta la dimensión intelectual del trabajo, como sucede en la industria más informatizada, en los servicios, las comunicaciones (Lazzarato y Negri, 2001); pero también en formas pretéritas de trabajo intensivo propias de los talleres del moderno trabajo esclavo, las economías de plantación, la minería extractiva, el trabajo forzoso, entre otras. 


\section{«Intelectualización» del proceso productivo}

El trabajo potenciado por la ciencia y la tecnología redunda en una mayor productividad del trabajo social e introduce cambios en los ámbitos de la producción. No obstante, se puede interpretar que es irrelevante si un obrero es más «intelectualizado» o si sólo es un mero obrero manual directo, incluso si está ubicado en el centro del proceso productivo, o si realiza una tarea considerada secundaria o colateral. Lo que importa desde la óptica del proceso de valorización es que desempeñe una función productiva, que contribuya en el proceso de creación de valores, dentro de la trama de valorización de capital, como parte del tejido social de un trabajo colectivo, del llamado «trabajo social combinado» (Marx, 1982b:953).

Desde la perspectiva del capital, el trabajo se ha «intelectualizado» en la medida que las facultades críticas y creativas del trabajador manual, es decir, su faceta intelectual, se subsumen y canalizan con el doble propósito de hacer eficiente el proceso de valorización y de enajenar la subjetividad crítica del trabajador, que eventualmente podría volcarse hacia la concientización, organización y acción política. En el modo sociotécnico de gestión del trabajo taylorista y fordista, el proceso de trabajo se determinaba desde el mirador de una gerencia con atributos tecnocientíficos que establecía los lineamientos que el trabajador manual tenía que realizar. Con el advenimiento del toyotismo, se pasó de lo meramente manual, operario, del trabajador, a la recuperación de la dimensión intelectual del propio trabajo manual, claro, desde el punto de vista del capital. Ahora se estimulaba la capacidad intelectual del trabajador con objeto de que el capital se la apropiara para su servicio.

Las condiciones de producción del trabajo social combinado en la actualidad tienden a subsumir lo improductivo en lo improductivo, o a 
desechar lo primero o transferirlo hacia empresas terciarizadas. De igual forma, se tiende a combinar lo «manual» con lo «intelectual» y a perfilar una fuerza de trabajo abstracta con mayores dosis de inversión intelectual; esto plantea que, en tanto trabajo humano indiferenciado, como consumo de energía física, muscular y nerviosa del obrero, también se requiere un consumo creciente de energía intelectual, cerebral, es decir, la pura fuerza física se combina con la potencia cognitiva para una mayor potencialización del trabajo productivo:

La propia forma valor del trabajo se metamorfosea. Ella asume crecientemente la forma valor del trabajo intelectual-abstracto. La fuerza del trabajo intelectual producida dentro y fuera de la producción es absorbida como mercadería por el capital que se le incorpora para dar nuevas cualidades al trabajo muerto (...). La producción material y la producción de servicios necesitan crecientemente de innovaciones, tornándose por eso cada vez más subordinadas a una producción creciente de conocimientos que se convierte en mercaderías y capital (Vicent, 1993, citado por Antunes, 2009:36).

Siendo un producto del trabajo humano, por tanto, trabajo muerto, la máquina informacional, con sus mecanismos de coordinación, almacenamiento y realización de tareas, mediante computadoras y software, comienza a realizar actividades que son propias de la inteligencia humana y a sustituir trabajo humano vivo, pero con funciones evidentemente más complejas que las máquinas convencionales. Más allá de la réplica de funciones mecánicas y ergonómicas, ahora las funciones cerebrales se objetivan en la máquina, y los saberes intelectuales y cognitivos, atributos insustituibles de los trabajadores, sobre todo de los altamente calificados, pasan 
paulatinamente a formar parte constitutiva del funcionamiento de la maquinaria informatizada. De tal suerte que de la subsunción formal y real del trabajo cognitivo en el capital, donde la premisa era el funcionamiento de la ciencia como capital y la subordinación de los científicos y tecnólogos a la lógica de valorización, ahora pasamos a la transferencia de las funciones intelectuales del hombre a la máquina informacional compleja.

Imbuido en el espíritu toyotista, el capital busca afanosamente subsumir la fuerza de trabajo en todas sus dimensiones, corporales e intelectuales, constriñéndola y deshumanizándola. El capital organiza la organización de los trabajadores y concede un momento de la jornada laboral para que los trabajadores se reúnan en «círculos de control de calidad» a fin de que discutan y aporten ideas sobre su propia actividad laboral, una medida que permite al capital apropiarse de la dimensión intelectual de quienes producen directamente en el piso de la fábrica, no en la oficina gerencial. En los sectores más avanzados, donde se usan máquinas «inteligentes» y mecanismos informatizados que requieren trabajadores más «calificados», estos mecanismos se tornan más complejos e intensivos. En esos sectores de punta se gestan, a su vez, nuevas máquinas, más «inteligentes», que realizan actividades otrora propias de los seres humanos, en procesos que articulan el trabajo vivo altamente diferenciado y el trabajo muerto más informatizado.

\section{Trabajo tecnológico: revolución cuaternaria, industria 4.0 y precarización digital}

Con la implementación de las nuevas tecnologías de la información y la comunicación (TICS), el capital impuso dinámicas disruptivas en el mundo 
del trabajo a nivel mundial, que redundan en la disminución del tiempo de circulación de las mercancías, más allá de si las mercancías son materiales o «inmateriales», tangibles o intangibles.

El teléfono celular y sus aplicaciones fungen como el nuevo grillete de los modernos esclavos sometidos a formas de trabajo sumamente precarizadas y degradantes. A diferencia del obrero industrial, el nuevo proletario de los servicios corresponde a una plataforma productiva orquestada desde la esfera digital y está encadenado al uso del teléfono celular, no como aparato de comunicación personal sino como herramienta de trabajo. Si el siglo XX estaba identificado con el automóvil, lo que va del XXI está signado por el teléfono celular, las redes digitales y el internet. Los niños, jóvenes y adultos, en cualquier lugar y momento, en todos los países, están conectados, digitando o hablando por ese dispositivo. El arquetípico obrero industrial con overol ha sido remplazado, suplementado o complementado por este prototipo de proletario. La gestación de un nuevo proletariado no es, sin embargo, un fenómeno de asalariamiento de la «clase media» sino más bien la expansión del asalariamiento en la órbita de los servicios.

La figura emergente, prototípica del «capitalismo digital», es el hombre cibernético, una especie de proletariado digital, que lo mismo puede trabajar en un local en convivencia con otros trabajadores, que hacerlo desde su casa, mediante el teletrabajo o el trabajo en casa (home office). La abundancia de trabajo realizado en la red digital tiene la peculiaridad de que a menudo tiende a hacer indistinto el trabajo propiamente dicho y el tiempo libre u ocio, más aún, muchas actividades que aparentemente se realizan como una forma de ocio son de hecho tareas que son apropiadas y metabolizadas como parte del trabajo o como parte de tareas que el consumidor realiza y ahorra al proveedor de servicios. Adicionalmente, 
este trabajador está teledirigido, pues al estar sujeto a redes digitales se considera que siempre estará disponible, en cualquier momento y lugar. El trabajo en casa ya no distingue horarios, días ni periodos de descansos, sólo reclama el cumplimiento de tareas, productos terminados, proyectos concluidos, actividades realizadas, reportes entregados. También es una modalidad que se convierte en una extensión del trabajo formal realizado en un centro de trabajo y que se traslada a la casa, donde se cumplen pendientes, trabajos urgentes $\mathrm{u}$ otros trabajos adicionales que pueden representar un trabajo adicional para quien lo realiza, por ejemplo, el profesor, investigador o periodista, sea por caso.

La denominada industria 4.0, el «internet de las cosas», responde al objetivo del capital más desarrollado de digitalizar y transformar la esfera productiva para disminuir la fuerza de trabajo, ser más productivos y obtener más ganancias. Se anuncia que esto impactará a todos los sectores, pero de manera desigual. En los países desarrollados del norte, cuando el internet de las cosas asuma el comando del mundo productivo, tentativamente los trabajadores menos calificados perderán su empleo debido a la digitalización de la producción o la informatización de la producción. También se crearán nuevos trabajos más calificados en la cúspide de la nueva configuración industrial, pero en menor cantidad y menor relevancia, por lo que la tendencia es hacia el desempleo por la tecnificación de vanguardia.

Previsiblemente, con la profundización de la «revolución 4.0» no ocurrirá una afectación en todos los ámbitos, sino que las profesiones más afectadas en términos de ocupación serán las de los asalariados, conforme avance la sustitución del trabajo manual por dispositivos digitales, la inteligencia artificial, la robótica y otras formas de automatismo y producción 
cibernética. En ese nuevo esquema, aquello que pueda ser subsumido a modelos digitales será reconvertido a esa lógica operativa. El problema es que si bien se crearán nuevos empleos, a la postre serán pocos para el cúmulo de trabajadores disponibles, y serán orientados hacia un sector laboral reducido y elitista, en tanto que aumentará el desempleo entre los sectores manuales, descalificados, que pueblan los sectores populares.

La implementación de dispositivos digitales para regular la explotación del trabajo y disfrazarlo de trabajo independiente o empresarial es un mecanismo muy difundido por corporaciones multinacionales (p. ej., Uber y Amazon), además de que ha sido presentado como una forma de «economía colaborativa» (p. ej., Uber y Airbnb). Sin embargo, las empresas que operan con plataformas digitales distan de ser «economías colaborativas», más bien son «compañías tradicionales que utilizan internet para intermediar y extraer las ganancias de muchos individuos conectados» mediante la formula de «trabajar mucho para que otros ganen» (Zuazo, 2018). Esta forma de gestión del trabajo responde a una estrategia empresarial de explotación encubierta de trabajadores para apropiarse de mayores márgenes de ganancia y aumentar la valorización del capital. Se vale del surgimiento de una nueva clase de trabajadores educados y asalariados en los campos de la alta tecnología, y tiene como correlato empleos invisibles en espacios como centros de llamadas, telemercadeo, hoteles, empresas de limpieza, comida rápida y cuidado de enfermos y mayores. Estos trabajos son muy precarios, dado que son del tipo estacional, a tiempo parcial, temporal, informal o independiente, con acceso a poca o ninguna seguridad o derechos.

El mundo digital, con su variedad y profusa difusión de plataformas, da forma y figura a la que se ha denominado "gig economy», (gig, que 
puede traducirse como «palomazo», en términos musicales, es decir, a una sola actuación o presentación) se ubica en el extremo opuesto del trabajo seguro, que tradicionalmente brindaba estabilidad y permanencia. La nueva modalidad de trabajos de este sector modulado por los avances tecnológicos recientes es el carácter temporal y parcelario, con la realización de determinadas tareas que forman parte de un proyecto específico, donde se fija la consecución de un objetivo concreto, mediante la realización de actividades intermitentes y flexibles. En este marco, la red de redes, internet, es el espacio virtual que se unge como el mecanismo mediador entre el capital y el trabajo. El trabajo digital que le es propio se parece a las formas también predominantes de trabajador «autónomo», por cuenta propia o freelance, esto es, formas laborales que adjudican tareas concretas realizadas en un término corto de tiempo, sin reconocer por ello exclusividad con la empresa contratante.

El fenómeno de la uberización abarca a la economía. La multinacional Uber cuenta con centenas de millares de trabajadores y sigue creciendo, porque se basa en captar a personas desocupadas — sean médicos, veterinarios, ingenieros o abogados - pero que tengan un auto, para que se afilien a esa empresa y puedan prestar un servicio de transporte y acceder a un ingreso que les permita sobrevivir. Los trabajadores conductores son tratados como si fuesen contratistas independientes y no como empleados informales. En el esquema de trabajo deben poner su propio automóvil y pagar los gastos, incluidos la reparación, mantenimiento, seguro y combustible. Uber utiliza como soporte operativo una aplicación digital y explota trabajo asalariado pero disfrazado como trabajo independiente y empresarial para apropiarse del plusvalor generado por los servicios de los conductores. La empresa dice que posibilita la relación entre el chofer y el 
consumidor mediante un software de aplicación móvil y para ello no contrata al trabajador; sin embargo, por cada servicio realizado por un chofer, la empresa se apropia al instante, a través de la aplicación, de un porcentaje de $20 \%$ o $25 \%$ o más del costo del viaje, lo cual supone una caudalosa renta tecnológica.

La ideología del emprendedor inoculada entre el común de los trabajadores es funcional al giro digital en la economía mundial, porque remarca el mito del hombre que se hace a sí mismo (self-made men) dentro del capitalismo que ofrece un horizonte de posibilidades para los más talentosos y empeñosos. Entre los trabajadores de la economía digital se fundan nuevas relaciones laborales sumamente precarizadas, por vía de la terciarización o precarización, pero imbuidas dentro de esa ideología meritocrática del individuo autodeterminado. En el paradigma impuesto de la uberización y su diseminación en otras esferas, los trabajadores no son considerados como empleados por las empresas donde laboran, sino que aparecen como «empresarios»o «trabajadores autónomos». Esta mistificación del trabajador es funcional porque terminan por formalizar un trabajador sin derechos, que no tiene ante sí un patrón y no pueden organizarse en sindicatos, como ocurría con generaciones precedentes de trabajadores. Asimismo, la mistificación de los trabajadores uberizados se complementa con la designación de esa forma de trabajo como «economía colaborativa» o «economía de plataformas» (Algar, 2007; Botsman y Rogers, 2011), la masificación de intercambios vía digital que opera con plataformas como Uber, Amazon, YouTube, TikTok, Facebook, Twitter, Airbnb, etcétera. Los trabajadores se registran en una plataforma digital sin ser reconocidos como trabajadores, sino que asumen el papel de emprendedores y aportan sus propios medios de producción y su fuerza de trabajo. En 
su actividad laboral producen información, datos y otros contenidos que la empresa capitaliza, mediante la venta de publicidad o el señorío de una renta tecnológica (Echeverría, 2005; Bolaño, 2013). Se trata de un trabajo productivo que genera valor agregado, pero se encubre al confundirse el papel del trabajo enajenado como un falso trabajador libre o autónomo. Las leyes laborales vigentes resultan obsoletas para reglamentar y regular estas nuevas modalidades de trabajo y las formas de organización de trabajadores están desfasadas.

El trabajo intermitente se ha expandido como forma de subyugación total de trabajadores que sólo son llamados para realizar un trabajo específico y sólo cobran por la hora trabajada, es decir, si no trabajan, no cobran. Se trata de un trabajador sujeto al teléfono celular donde recibe los llamados para trabajar, por ejemplo, en un restaurante de comida rápida, un servicio médico, la limpieza en una casa, la jardinería, la conducción de un auto o cualquier otra actividad. Se convierte en una suerte de «esclavo digital» o infoproletariat (infoproletariado) (Antunes, 2018). Esta modalidad laboral elude los derechos laborales, aunque se simule cubrirlos cuando se rebaja la hora pagada, y si bien se incorpora el aguinaldo, vacaciones y otros rubros similares, se hace sobre la base de un salario bajo y un trabajador a disposición permanente.

En el Reino Unido, Holanda y otros países opera el llamado contrato de cero horas (zero hours contracts). Mediante esta forma de contrato, el empleador, una empresa que se trasviste como una «aplicación» digital (App), no está obligado a llamar al trabajador disponible y el trabajador tampoco está obligado a aceptar el trabajo. En lugar de trabajar un número determinado de horas fijas o turnos establecidos, los trabajadores están a la expectativa esperando una llamada para hacer una obra determinada, a disposición 
permanente de sus jefes, y se les paga sólo por el tiempo que trabajen, pero no por lo que hayan esperado. Esta modalidad opera, sobre todo, en los servicios, en las más distintas actividades, como medicina, abogacía, trabajo doméstico, trabajo de cuidados, electricidad, limpieza, etcétera. Las empresas utilizan la tecnología de la información como un método de flexibilización total del trabajo. Este modelo de contrato se ha difuminado en el mundo como forma de aprovechar a la masa de trabajadores disponibles para ser llamados a realizar trabajos ínfimos. Es el paraíso laboral para el capital, que exprime a la clase trabajadora únicamente cuando la necesita. ${ }^{4}$

\section{Espectros del trabajo no asalariado subsumido al capital}

\section{Pervivencia del trabajo campesino}

El capital ha expandido los dominios de la explotación, y abarca no sólo a las fábricas y establecimientos convencionales, sino a todos los ámbitos de la vida, e incluye en su tráfago formas de trabajo colaborativo y

${ }^{4}$ Representa una tendencia global, no necesariamente idéntica al sistema de cero horas. En Italia se implementó, aunque fue impedido por la presión sindical, una forma de «trabajo pagado por váucher», donde los trabajadores eran llamados para trabajar determinadas horas por semana o mes y recibían un váucher equivalente a las horas laboradas y ese papel era cambiado por el equivalente al salario mínimo por hora. Es una forma de precarización legal. Aunque también se creó una precarización ilegal cuando los empresarios ampliaban la jornada de trabajo, pero pagaban por debajo del equivalente a lo estipulado por váucher. El problema es que hay trabajadores desempleados, inmigrantes y locales, que presionan a los ocupados en una espiral descendente de desvalorización de la fuerza de trabajo, por lo que se impone el capital. En Portugal hubo una variante llamada «recibos verdes»: la persona trabaja, cobra el recibo y, con él, el equivalente a ese trabajo. En Inglaterra ha habido medidas judiciales que obligaron a las empresas a pagar derecho de trabajo. 
cooperativo, formas de trabajo en común que utilizan códigos abiertos y compartidos, que podrían significar formas de trabajo autónomo pero que terminan por ser subsumidos por el capital.

El campesinado representa un segmento de las clases populares que persisten en el capitalismo global. Más de 90\% de los agricultores del mundo son campesinos e indígenas (con la advertencia de que la primera es una categoría social y la segunda antropológica), pero disponen de menos de un cuarto de la tierra agrícola (GRAIN, 2014). En su mayoría se trata de productores directos poseedores de pequeñas extensiones de tierra, condenados recurrentemente a desaparecer de la faz del capitalismo, pero que aún persisten y recrean modos de vida y trabajo anclados en una cultura material de reproducción socioambiental (Bartra, 2006). Sin embargo, tienen la capacidad de alimentar al mundo (Vía Campesina, 2011), no obstante que se ha expandido la agroindustria que se reconvierte con nuevas tecnologías, actualmente insertadas en la llamada segunda revolución verde, y la concentración de grandes capitales dentro de cadenas globales de producción. No obstante, el campesinado habita en el otro hemisferio del mundo del trabajo, habitualmente relegado, del medio rural, que no obstante aún retiene a $46 \%$ de la población mundial. El campesinado es uno de los sectores más atacados y vulnerables en el capitalismo neoliberal: sufren por la nueva regulación de los mercados, favorable a los monopolios agroindustriales; el precio de las cosechas es determinado por oleadas especulativas en las bolsas, en Chicago; en lugar de una reforma agraria restitutiva se imponen la políticas de despojo y acaparamiento de tierras; la imposición de monocultivos de exportación y semillas transgénicas destruyen la biodiversidad; la importación indiscriminada de alimentos subsidiados aplasta a los productores dejados a su suerte, etcétera. 


\section{Aumento del trabajo femenino}

La clase trabajadora siempre ha estado compuesta por hombres y mujeres, pero ahora la proporción está cambiando con el incremento del trabajo femenino en la industria y en los servicios en la economía global. En diversos países, la proporción de mujeres que trabajan ha superado a la de los hombres, y en algunas actividades específicas es abrumadoramente mayoritaria, como ocurre en determinadas plantas de ensamble. Inclusive, cuanto más se incrementa el trabajo a tiempo parcial, la fuerza de trabajo femenina crece en términos proporcionales.

La incorporación creciente de las mujeres al mercado laboral se ha considerado como una forma de emancipación femenina, pero desde la óptica del capital, este movimiento ha servido para profundizar la división sexual del trabajo y el aprovisionamiento de una corriente inagotable de fuerza de trabajo barata. Se han diseñado determinadas áreas de especialidad laboral, por ejemplo, en sectores intensivos en capital con manejo de maquinaria avanzada predominan los hombres, y en las áreas de mayor trabajo intensivo, donde prevalece la explotación del trabajo manual, suele ocuparse a un número mayor de mujeres. Sintomáticamente, cuando no se destinan esos empleos a las mujeres, se opta por ocupar a trabajadores de minorías raciales o inmigrantes, o bien a niños o una mezcla de estos sectores que se colocan en las condiciones más precarias, inseguras e intensivas.

\section{Exclusión de jóvenes}

Desde la óptica generacional, pero con intenciones de acentuar la precarización, el mercado de trabajo está excluyendo crecientemente a la fuerza 
de trabajo de los jóvenes y los adultos mayores. En buena medida, los jóvenes son egresados de los estudios medios o superiores que no encuentran empleo, lo mismo en los países desarrollados y subdesarrollados. Sin embargo, los jóvenes no son una categoría de clase sino un estrato demográfico acorde a un rango de edad con una composición multiclasista, además de distintos niveles de formación educativa y cultural, vínculos con los grupos de poder y posibilidades de inserción laboral. Los trabajadores de 40 años o más, que el capital desprecia y considera «viejos», cuando caen en el desempleo no pueden reingresar en el mercado de trabajo, y son obligados a tomar empleos informales, parciales, etcétera. En los últimos años han desaparecido determinadas profesiones o funciones que redundan en el desempleo para quienes desempeñaban esas labores retiradas, y difícilmente tendrán condiciones favorables para reinsertarse ostentando una nueva profesión o especialidad, sin contar que se encontrarán en desventaja frente a trabajadores jóvenes que disponen de capacidades polivalentes y multifuncionales, inclusive la predisposición a recibir un salario inferior. El veterano profesionista desempleado es orillado a integrarse al desbordante ejército industrial de reserva.

Las perspectivas de la clase trabajadora se constriñen a que sus empleos disminuirán más todavía, y en ese movimiento se acrecentará el desempleo de jóvenes calificados (Márquez, 2019). Paradójicamente, los jóvenes con título de licenciatura y posgrado ingresan al mercado laboral en empleos donde no se requieren las calificaciones especializadas que detentan, y la formación de ingenieros, economistas, contadores u otra se frustra laborando en hoteles, restaurantes, taxis y demás. Ante ese panorama, los estudiantes que cursan una maestría o doctorado no tienen certeza de dónde podrán trabajar y en qué condiciones. En muchos casos, egresados 
universitarios de posgrados con el dominio de varios idiomas, no tienen empleo en un ámbito laboral afín al que fueron formados. Un sector de jóvenes cosmopolitas deambula por el mundo, sobre todo en países que representan señuelos tecnocientíficos, como China, India, Japón, Estados Unidos y otros. Previsiblemente, con el despliegue de la industria 4.0 se creará una gama nueva de empleos con mayor nivel de calificación y remuneración acorde al conocimiento informacional digital, pero en una proporción muy inferior a la sobreoferta de egresados universitarios que se perfilan en esa dirección, y en el ámbito de las empresas no se amortiguará el déficit en tanto no se incremente la cuantía y proporción de asalariados en relación con los parámetros actuales. Es sabido que transformaciones en el ámbito laboral impulsadas por el cambio tecnológico no se implementan para generar empleos sino para generar mayor productividad, ganancias empresariales y rentas tecnológicas.

\section{Trabajadores desechables}

En el capitalismo contemporáneo se desencadena la existencia abrumadora de una sobrepoblación flotante. Se trata de una fracción creciente del proletariado moderno que se conforma como un sujeto colectivo despojado, explotado y violentado. Al estar a expensas del capital global, se transfigura en un proletariado internacional a disposición del capital, que lo toma y lo deja, en sus propios países de origen o los absorbe en las economías sedes del gran capital.

La sobrepoblación abundante, desorganizada y precarizada representa la masa laboral fresca, fácilmente explotable y desechable. En el capitalismo contemporáneo, la sobreoferta de fuerza de trabajo prohíja una 


\section{Morfología del tRABAjo EN El CAPITALISMO GLOBAL}

población excedentaria relativa, que desde etapas previas del desarrollo capitalista Marx identificara como flotante, latente o estancada:

La contradicción entre capital y trabajo asalariado se desarrolla hasta su completa contraposición, en cuanto el capital es el medio no solamente de la devaluación de la fuerza de trabajo viva sino también de la transformación de esta última en superflua, ya sea completamente en determinados procesos, o bien reduciéndola al menor número posible. El trabajo necesario se transforma de esa manera en población superflua, en la medida en que no sirva para obtener plusvalor (Marx, 1982c:186).

En la era del capital global, su composición adquiere nuevas dimensiones a nivel mundial, debido a la enorme expansión y circulación de fuerza de trabajo migrante a escala global, detonante de la multiplicación de los mecanismos de explotación, intensificación y precariedad laboral (Márquez, 2010b). En conjunto, las modalidades de explotación del trabajo experimentan transmutaciones constantes, las cuales son catapultadas por la irrefrenable expansión de la población excedentaria relativa, que sirve al capital como soporte para precarizar a los trabajadores e incrementar los niveles de explotación. Esto sirve para fragmentar a la clase trabajadora, que de antemano está diferenciada por ramas, sectores y la división internacional del trabajo, sobre todo entre el centro y las periferias del sistema mundial capitalista.

En el capitalismo global, los trabajadores se han convertido en una mercancía desechable y despreciable. Una masa desbordante de trabajadores se sumerge en los mares del desempleo estructural y se suma al ejército industrial de reserva mundial. Se trata de un proletariado internacional a 
disposición permanente del capital global, que se usa como «peso muerto» y mecanismo de regulación para jalar hacia la baja los niveles salariales.

\section{Proletariado nómada}

Los nuevos nómadas son los trabajadores que se mueven por distintos países del mundo y que están desesperados por encontrar cualquier trabajo, por más precario que este sea, el cual ni siquiera podrán encontrar en su país de origen. El tránsito de migrantes forzosos, con la fuga desesperada de países en guerra, en crisis o en desempleo estructural, se traduce en un incremento de refugiados, más aún, en una crisis humanitaria de trabajadores sin ninguna protección, expuestos a la violencia descarnada del Estado o de grupos criminales, además del rechazo de la sociedad civil de los países por donde cruzan y arriban.

Se trata de un sujeto colectivo despojado, violentado y excluido, del proletariado internacional desechable que se torna en migrante forzado (Márquez, 2013). Al ser abandonado a su suerte, se convierte en víctima propiciatoria del capital global, que lo despoja, lo desecha, lo expulsa, y entonces está expuesto de manera permanente a la violencia estatal y criminal. El proletariado nómada está en la búsqueda de realizarse como mercancía humana, de venderse como fuerza de trabajo. Los migrantes que logran ingresar en las economías centrales, como Estados Unidos, Inglaterra, Francia o Alemania, buscan cualquier tipo de trabajo. No disponen de la fuerza ni la organización para negociar un empleo seguro y bien remunerado, y en la mayoría de los casos aceptan empleos precarios, sin derechos. Para sobrevivir, aceptan el primer trabajo que logre conseguir. En términos macro, este 
esquema de movilidad genera presiones en los mercados laborales, que tienden hacia el aumento de formas laborales precarias donde tienen cabida la masa creciente del proletariado internacional nómada, la masa de trabajadores que deambulan por el mundo. Pero también los migrantes forzados no logran, necesariamente, arribar a su destino, y entonces se van quedando en el camino, son detenidos o deportados o se quedan a trabajar en países de «tránsito» en puestos de trabajo paupérrimos.

El migrante forzoso puede tornarse, y de hecho lo es en algunos casos, en un sujeto que será apoyado por grupos de la sociedad civil, defensores de derechos humanos y, en algunos casos, del Estado, y se le da el tratamiento como víctima. Pero en menor medida se ha transfigurado en un sujeto político, que reconozca los motivos de su conversión en migrante forzoso, las condiciones de explotación y opresión a las que será mayormente sometido y las vías de emancipación que se pueden tejer.

El proletariado nómada es, resueltamente, trabajo vivo en movimiento. Y en tanto fuerza de trabajo disponible se combina con el uso alternativo de métodos de explotación y superexplotación, que coexisten en un contexto donde se difunden avances científico-tecnológicos y formas arcaicas de producción que rememoran y le imprimen vigencia a formas de servidumbre, esclavismo y trabajo forzado. De tal suerte que la «industria de la migración» permite a algunos países subdesarrollados especializarse en la exportación de fuerza de trabajo barata, abundante y desorganizada, y en la importación de capitales que saquearán recursos naturales y sobreexplotarán fuerza laboral aún cautiva y transferirán valor por vías directas e indirectas (Márquez, 2012). La sustancia viva de la capacidad de trabajo humana seguirá rutas contradictorias para ofrendar su vitalidad al Moloch, al gran dinero. 


\section{Generalización de la superexplotación del trabajo}

La explotación superlativa de la fuerza de trabajo adquiere la forma de superexplotación cuando se remunera la fuerza de trabajo por debajo de su valor, como uno de los mecanismos para afrontar la caída tendencial de la tasa de ganancia (Marx, 1981), pero se convierte en un rasgo estructural en las economías periféricas que disponen de una composición orgánica de capital predominantemente subdesarrollada y que no están en condiciones de afrontar la competencia mundial, por lo que transfieren el costo a la fuerza de trabajo que explotan. Con la inserción a los mercados articulados por la globalización, la superexplotación se convierte en un mecanismo generalizado - y no sólo como un método provisional de contención de la caída de la tasa de ganancia- que se extiende también hacia las economías desarrolladas mediante la emigración forzada de trabajadores de las periferias a los centros, que se ocupan en sectores laborales sumamente degradados, precarizados e inseguros, que remuneran por debajo del valor de la fuerza laboral de la economía receptora, pero así mismo con la adopción de la política de precarización y flexibilización laboral, esta forma de desvalorización laboral se expande a otros sectores laborales hasta convertirse en un rasgo estructural del capitalismo global. La superexplotación generalizada cobra carta de naturalización con el aumento de la informalidad, la subcontratación y la incertidumbre en la fuerza laboral internacional, pero no sólo en el mundo subdesarrollado sino también en el desarrollado.

El régimen de superexplotación de la fuerza de trabajo, que se había destacado como un rasgo estructural del capitalismo subdesarrollado, tiende a generalizarse en el capitalismo global y alcanzar a los países centrales, mediantela incorporación continua de inmigrantes de las periferias, 
a los que mayormente se confina en sectores laborales degradados, inseguros y mal pagados, como por el hecho de que se implementan políticas laborales y salariales que desvalorizan en términos generales el mercado laboral (Sotelo, 2019).

\section{Embestida del capital}

Lo que se entiende por neoliberalismo es, ante todo, un método generalizado para afrontar la caída secular de la tasa de ganancia y transferir una parte del fondo de vida obrero al fondo de acumulación del capital. Para que esto sea posible, se han implementado las consabidas políticas de ajuste estructural, tales como la privatización, desregulación y liberalización, entre otras, pero también la formación de una economía mundial de trabajo barato (Chossudovsky, 2002).

La pulsión destructiva del capital, merced a la competencia, las innovaciones tecnológicas, las crisis y los recortes en costos laborales, se ha recrudecido en la últimas tres décadas y media. Después de la crisis capitalista de los setenta, el programa «neoliberal» asociado al toyotismo y otros mecanismos de desregulación, flexibilización y precarización, han endurecido las políticas antiobreras y, en conjunción con la reestructuración productiva del capital, implementan una reestructuración capitalista y un reacomodo del entramado social.

El capital intensifica una estrategia conjunta para incrementar las ganancias y ahondar su acometida contra el trabajo, por lo que en esa reyerta se acrecienta el desempleo y la desvalorización de salarios directos, indirectos y diferidos. 
Al desempleo y desvalorización del trabajo se agrega el incremento de la pauperización de las clases populares y la frustración de las camadas de jóvenes con educación universitaria que enfrentan un mercado laboral estrecho y pauperizado. El mundo de la producción crecientemente digitalizado en la industria, agricultura y servicios coexiste con abundantes reservorios de trabajadores desempleados. A las filas del desempleo se incorporará un desempleo de trabajadores desmoralizados por los puestos de trabajo precarios, parciales y temporales. A nivel agregado, se forma una clase obrera mundial de enormes proporciones y, de manera concomitante, el desempleo estructural se expande (Husson, 2015).

En el corto plazo, el modelo económico y la gestión estatal de la producción y la macroeconomía pueden influir en los niveles de empleo o desempleo, pero los cambios tecnológicos en la producción y su profundización con mecanismos automatizados y digitalizados generan una escalada descendente de empleos y la propagación de la miseria. En contraste, el gran capital industrial financista, especulativo y rentista, acumula mucha más riqueza de la que son capaces de producir millones y millones de trabajadores pobres. El avance tecnológico, gestionado según los intereses del capital, propicia el aumento y concentración de las ganancias. Desde la perspectiva de los trabajadores, el avance tecnológico podría orientarse a la reducción del trabajo extenuante y la jornada de trabajo, para hacer realidad la utopía de que las clases trabajadoras vivan dignamente dentro y fuera del ámbito del trabajo, de tal modo que disminuyan el tiempo de trabajo a dos o tres horas por día y que en las horas liberadas desarrolen actividades que impriman un sentido y significado a la vida propia. Obviamente, la ampliación del tiempo libre sólo será posible mediante la reducción del tiempo de trabajo. Además, se requiere combatir la lógica 
destructiva propia de la producción dominada por el valor de cambio y el trabajo enajenado, que se orienta a enriquecer a las clases propietarias y a los gestores del capital que controlan los circuitos financieros, productivos y distributivos, además de que regulan los mercados laborales y la producción.

Por lo pronto, la incesante restructuración del capital tiene como eje central la reducción de los costos laborales. Esto se logra incrementando la composición orgánica del capital, es decir, una mayor proporción de maquinaria y equipo provistos de mejor tecnología (trabajo muerto) y una menor participación de la fuerza de trabajo (trabajo vivo). Evidentemente, el imperativo empresarial es reducir costos laborales y aumentar la productividad del trabajo, esta premisa se aplica permanentemente en todas las actividades, desde la manufactura, la agroindustria y la minería, pasando por los servicios hospitalarios, educativos y turísticos, hasta las telecomunicaciones, el comercio, el centro de llamadas, la telemercadotecnia (telemarketing) y otras modalidades que se incorporan a la esfera de la distribución y el consumo.

El capital y el Estado, en tanto formas asociadas del capital colectivo, instrumentan políticas para constreñir el mundo laboral. El trabajo se intensifica, los derechos laborales se erosionan, la fuerza laboral se precariza y superexplota, el empleo se informaliza. El despotismo de los jefes, supervisores y coordinadores se acrecienta, a la vez que aumenta la presión para cumplir los objetivos de la productividad siempre al alza, en tanto que los salarios se aminoran, los horarios de trabajo son maleables y cunde el hostigamiento, las enfermedades y la muerte. En términos sociales, se profundiza el proceso de proletarización y se conduce mediante pautas violentas, y en ese caldo de cultivo emerge la figura de un nuevo tipo de proletariado 
anclado, sobre todo, en los servicios, que se expande y desborda a nivel mundial, y en consecuencia diversifica y amplifica al conjunto de la clase trabajadora. El trabajo asume una nueva composición con repercusiones contradictorias o incipientes en las formas de organización, representación y lucha de la clase trabajadora en el planeta.

\section{Horizontes emancipatorios}

Las luchas contra el dominio del capital están centradas en la relación capital-trabajo, pero también aluden a múltiples formas de opresión concomitantes a ese nexo crítico. En tanto que la clase trabajadora se compone de hombres y mujeres, cualquier proyecto de emancipación no podrá ser una reivindicación de la clase masculina, ni sus organizaciones, como sindicatos o partidos, comandadas por hombres. La opresión del capital es de clase, pero también de género, que es una relación precapitalista, pero perdura en el capitalismo y, si fuera el caso, seguirá en una eventual sociedad poscapitalista si no es eliminada de las relaciones sociales, entre hombres y mujeres.

La emancipación del trabajo respecto del dominio del capital y la emancipación de las relaciones opresivas entre géneros son componentes constitutivos de la emancipación del género humano frente a todas las formas de opresión y dominación. Al igual que lo ha sido la rebeldía de los negros contra el racismo de los blancos, la lucha de los trabajadores inmigrantes contra el nacionalismo xenófobo, la lucha de los homosexuales contra la discriminación sexual, entre otras formas de opresión contra el ser social en el capitalismo contemporáneo. 
En nuestros días, la emancipación humana significa una revolución en el mundo del trabajo, sobre el trabajo, por los trabajadores, y en aras de desenajenar el trabajo para convertirlo en una actividad humana libre y colectiva. Entraña un proyecto social complejo, más complicado que en épocas precedentes, puesto que ahora reconstruir el sentido de pertenencia de clase y la concientización de los trabajadores resulta un logro más difícil, amén de que el capital colectivo dispone de diversas formas de dominación, entre las cuales destacan el Estado y sus coaliciones imperialistas, la política embaucadora, la industria cultural alienante, la religión fetichista y la ideología encubridora. Tales formas superestructurales logran mistificar la problemática subyacente en la estructura social y la encausan convenientemente hacia los intereses supremos de la valorización del capital y sus formas de reproducción social.

Las luchas sociales arrojan resultados impredecibles que, en todo caso, dependen de la correlación de fuerzas, más específicamente de la capacidad de organización, resistencia y lucha de las clases trabajadoras. En esta perspectiva, es menester dilucidar las posibilidades de que los dos polos de la clase trabajadora, el viejo y nuevo proletariado, los estables y los precarios, sean capaces de establecer relaciones de solidaridad, tejer alianzas, generar una conciencia de clase, es decir, pasar por un proceso de formación político-cultural de clase con el propósito de formar un sólido poder de clase articulado frente a la lógica y poder acrecentado del capital instituido.

En razón de ello, reconocer la amplitud, heterogeneidad y fragmentación del proletariado moderno, que incluye a la masa desbordante de trabajadores de servicios precarizados, es un tema crucial para fomentar una conformación orgánica de la clase trabajadora ampliada, así como la internacionalización de la clase, más allá de los divisionismos nacionalistas, 
étnicos y de género. Estas cuestiones serán decisivas en las luchas sociales venideras y en el desarrollo y eventual superación del capitalismo durante el siglo XXI.

El omnipresente capital financiero y su variedad de instrumentos (créditos, fondos de inversión, fondos de pensiones, derivados, bursatilización, paraísos fiscales, banca en la sombra, etcétera) asaltó y subvirtió el ámbito de la producción mediante políticas e instrumentos, como la flexibilización, financiarización y desregulación. Los Estados nacionales imponen reformas que erosionan los derechos laborales, precarizan a los trabajadores y disminuyen la responsabilidad social del Estado y del capital. Estas medidas draconianas no reconocen límites, a no ser que enfrenten la resistencia de los movimientos sindicales y la clase trabajadora, la cual suele ser abatida o atenuada por los Estados y atacada por los medios masivos de comunicación. En Francia, por ejemplo, se experimentan luchas sociales reivindicativas de los derechos laborales, pero también en otros países ha habido intentos, así sean fallidos, como en Argentina, para bloquear la reforma laboral, una lucha que se repite en otras partes del mundo, en la medida en que la embestida antiobrera es global.

Inscritas en los nuevos ciclos de lucha, los trabajadores que se reconocen como precarizados han desplegado marchas y huelgas en varios países. Por ejemplo, el movimiento Precários Inflexíveis en Portugal, el movimiento los Indignados en España, protestas en Inglaterra, los Occupy Wall Street, el movimiento San Precario y la Confederazione Unitaria di Base y la Nuove Identità di Lavoro en Italia. En esa línea, pueden considerarse además los movimientos juveniles (primavera árabe), los movimientos antineoliberales latinoamericanos con sus gobiernos «progresistas» $\mathrm{y}$ los movimientos contra los megaproyectos. 
Además de los conflictos entre capital y trabajo, burgueses y proletarios, aflora otra serie de conflictos. Al menos, destacan dos filones con alusiones al orden sistémico: el sexismo patriarcal y el racismo colonial (Federici, 2010; Mbembe, 2011). Entre los siglos XX y XXI, los espacios donde predominaba la ruralidad, las comunidades y los campesinos han sido espacios de resistencia y revolución dentro del capitalismo (las revoluciones mexicana, rusa, china, cubana; los movimientos de liberación nacional asiático, africano y antiimperialismo indio). Las denominaciones de clase se entreveraron con las nociones de colonialismo y racismo. Mientras tanto, en las metrópolis cobraban fuerza movimientos ambientalistas, pacifistas, feministas y estudiantiles, que eran considerados como agregados multiclasistas.

El capitalismo plantea como mecanismo de inclusión el trabajo enajenado y la servidumbre forzada se presenta como un privilegio. Hoy, como ayer, como mañana, se plantea el desafío de superar este orden social, pero una tarea de tal magnitud sólo será posible si los trabajadores mismos luchan por la emancipación humana.

El Estado, en tanto forma de poder que representa los intereses del capital colectivo, no ofrece grandes expectativas a las clases trabajadoras y los sectores populares en general. Pero parece ser determinante que los asalariados y la clase trabajadora en general rechacen decididamente la embestida y destrucción de la legislación que protege el trabajo, y obliguen al Estado a revertir esas medidas e impedir otras más. Las reformas laborales que permiten la precarización, la subcontratación y la flexibilización laboral se imponen sin legitimidad o engañando a la población haciendo creer que se generará crecimiento, empleo y bienestar, además de derechos y ventajas para los trabajadores, cuando ocurre precisamente lo contrario: cunde el desempleo y la pérdida de derechos. 
En la lucha parlamentaria y la lucha social debería de impulsarse la revocación de la legislación laboral que avala la subcontratación o terciarización, incluyendo las reformas jubilatorias que extienden las edades de retiro y disminuyen los recursos disponibles del salario diferido a sus beneficiarios, inclusive se genera la sensación de que los asalariados podrán ejercer sus derechos de jubilación en una edad en que tendrán un margen de vida muy estrecho antes de la muerte, si es que logran llegar a ese estadio, pues pareciera que de eso se trata.

Con todo, el desafío es mayúsculo si lo que se pretende es articular lo desarticulado, organizar a los desorganizados, es decir, a los trabajadores, los sindicatos y las luchas obreras, además de vincularse con las varias luchas sociales dispersas que no asumen la identidad proletaria, pese a que en su seno sean mayoría los trabajadores. No obstante, también es necesario actualizar el debate de ideas y proyectos políticos, quehacer que quedó en puntos suspensivos cuando libraban la batalla ideológica los polos geoestratégicos del capitalismo y el socialismo, con el aparente triunfo del primero y el desmoronamiento del segundo. Pero, la historia lo ha demostrado, el capitalismo es un producto histórico que para asentarse y desplegar su potencial requirió de cuando menos tres siglos, entre el Renacimiento y la Revolución Industrial, y ciertamente no es infinito, sino que tiene vida perecedera. En contraste, el proyecto socialista y comunista no ha conocido sus mejores días, inclusive pudiera argumentarse que no se ha gestado todavía o que no ha logrado desarrollarse en pleno sentido. Las experiencias de corte socialista han sido efímeras, incompletas y derrotadas, entre las más destacadas se puede mencionar a la Comuna de París a finales del siglo XIX, y a múltiples tentativas malogradas a lo largo del siglo XX, desde la revolución de octubre en Rusia hasta la revolución en China, 
además de las revoluciones verificadas en África y América Latina. Más allá de un necesario balance crítico de estas experiencias, se nos plantea un importante desafío en la actualidad: pensar de nueva cuenta un modo de vida que resignifique el trabajo, replantee la cuestión social, reconstruya la problemática ambiental, cristalice la igualdad de género entre hombres y mujeres, propicie la igualdad de clases, géneros y etnias. La emancipación humana será una conquista de las fuerzas sociales colectivas.

\section{Referencias}

Algar, R. (2007). «Collaborative consumption». Leisure Report, 4, pp. 72-83.

Amin, S. (1989). El eurocentrismo. Crítica de una ideología. México: Siglo XXI.

Amin, S. (2012). El capitalismo contemporáneo. El viejo topo.

Antunes, R. (2009). «Diez tesis sobre el trabajo del presente (y el futuro del trabajo)». Trabajo, empleo, calificaciones profesionales, relaciones de trabajo e identidades laborales, vol. I. Buenos Aires: Clacso.

Antunes, R. (2018). «The New Service Proletariat». Monthly Review, 69(11).

Bartra, A. (2006). El capital en su laberinto. De la renta de la tierra a la renta de la vida. México: UACM/Itaca.

Berardi, F. (2003). La fábrica de la infelicidad. Nuevas formas de trabajo y movimiento global. Madrid: Traficantes de Sueños.

Bernardo, J. (2009). Economia dos conflitos sociais. Expressão Popular.

Bolaño, C. (2013). Industria cultural, información y capitalismo. Barcelona: Gedisa.

Botsman, R. y Rogers, R. (2011). What's mine is yours: how collaborative consumption is chan-ging the way we live. London: HarperCollins Publishers. 
Boutang, Y.M. (2004). «Riqueza, propiedad, libertad y renta en el capitalismo cognitivo». En VV.AA, Capitalismo cognitivo, propiedad intelectual y creación colectiva. Madrid: Traficantes de Sueños.

Braverman, H. (1984). Trabajo y capital monopolista. La degradación del trabajo en el siglo XX. México: Nuestro Tiempo.

Chossudovsky, M. (2002). Globalización de la pobreza y nuevo orden mundial. México, Siglo XXI.

Coduras, A., Levie, J., Kelley, D.J., Sæmundsson, R.J. y Schøtt, T. (2010). Global Entrepreneurship Monitor Special Report: A Global Perspective on Entrepreneurship Education and Training. Global Entrepreneurship Monitor.

Coriat, B. (1992). Pensar al revés. Trabajo y organización en la empresa japonesa. México: Siglo XXI.

Dussel, E. (2014). 16 tesis de economía politica. Interpretación filosófica. México: Siglo XXI.

Echeverría, B. (2005). «Renta tecnológica〉 y capitalismo histórico». Mundo Siglo XXI (2).

Engels, F. [1875] (2003). La revolución de la ciencia de Eugenio Dühring ("Anti-Dühring')). Moscú: Editorial Progreso/Marxists Internet Archive.

Engels, F. [1845] (2020). La situación de la clase obrera en Inglaterra. Madrid: Akal. Federici, S. (2010). Calibán y la bruja. Mujeres, cuerpo y acumulación originaria. Madrid: Traficantes de Sueños.

Felix, G. y Guanais, J. (coords.) (2019). Superexplotación del trabajo en el siglo XXI. Bremen: El Tiple.

Frank, A.G. (1973). Lumpenburguesía: lumpendesarrollo. Dependencia, clase y política en Latinoamerica. Buenos Aires: Ediciones Periferia.

GRAIN (10 de junio de 2014). «Hambrientos de tierra: los pueblos indígenas y campesinos alimentan al mundo con menos de un cuarto de la tierra agrícola 


\section{Morfología del tRABAjo EN El CAPITALISMO GLOBAL}

mundial». Recuperado de https://www.grain.org/es/article/entries/4956hambrientos-de-tierra-los-pueblos-indigenas-y-campesinos-alimentan-almundo-con-menos-de-un-cuarto-de-la-tierra-agricola-mundial

Hinkelammert, F. y Mora, H. (2001). Coordinación social del trabajo: mercado y reproducción de la vida humana. San José: DEI.

Husson, M. (2015). «La formación de una clase obrera mundial». A través del espejo, 1(1).

Kamata, S. (1983). Japan in the passing lane. An insider's account of life in a japanese auto factory. New York: Pantehon Books.

Lazzarato, M. y Negri, A. (2001). Trabajo inmaterial. Formas de vida y producción de subjetividad. Río de Janeiro: DP\&A.

Lenin, V.I. (1966). El imperialismo, fase superior del capitalismo. Pekin: Ediciones de Lenguas Extranjeras.

López Villafañe, V. y Uscanga, C. (coords.) (2015). Japón después de ser el número uno. Del alto crecimiento al rápido envejecimiento. México: Siglo XXI.

Marini, R.M. (1973). Dialéctica de la dependencia. México: Era.

Márquez, H. (2010a). «Crisis del sistema capitalista mundial: paradojas y respuestas». Polis (27).

Márquez, H. (2010b). «Desarrollo y migración: una lectura desde la economía política crítica». Migración y Desarrollo (14).

Márquez, H. (2010c). «La gran crisis del capitalismo neoliberal». Andamios, 7(13).

Márquez, H. (2012). El mundo al revés. La migración como fuente de desarrollo. México: Miguel Ángel Porrúa.

Márquez, H. (2013). «El redoble de la migración forzada: inseguridad, criminalización y destierro». Migración y Desarrollo, 11(21).

Márquez, H. (2017). «Urdimbres de la crisis del capitalismo: proceso histórico y colapso civilizatorio». Estudios Críticos del Desarrollo, VII(12). 


\section{Humberto MÁrquez CovarRubias}

Márquez, H. (2019). «Crisis de la universidad pública y perspectivas de transformación». Observatorio del Desarrollo, 8(22).

Márquez, H. y Delgado, R. (2011). «Signos vitales del capitalismo neoliberal: imperialismo, crisis y transformación social». Estudios Críticos del Desarrollo, I(1).

Marx, K. (1971). El capital. Libro I. Capítulo VI (inédito). México: Siglo XXI.

Marx, K. (1975). El capital. El proceso de producción del capital, tomo I, vol. 2. México: Siglo XXI.

Marx, K. (1981). El capital. El proceso global de la producción capitalista, tomo III, vol. 6. México: Siglo XXI.

Marx, K. (1982a). El capital. El proceso global de la producción capitalista, tomo III, vol. 7. México: Siglo XXI.

Marx, K. (1982b). El capital. El proceso de producción del capital, tomo I, vol. 3. México: Siglo XXI.

Marx, K. (1982c). Progreso técnico y desarrollo capitalista. México: Cuadernos de Pasado y Presente.

Marx, K. (1988). El capital. El proceso global de producción capitalista, tomo III, vol. 8. México: Siglo XXI.

Marx, K. [1844] (2001). Manuscritos económicos y filosóficos de 1844. Recuperado de https://www.marxists.org/espanol/m-e/1840s/manuscritos/

Marx, K. y Engels, F. (2001). Manifiesto comunista. Madrid: Alianza.

Mazzucato, M. (2017). El Estado emprendedor. Mitos del sector público frente al privado. Barcelona: RBA.

Mbembe, A. (2011). Necropolítica. Santa Cruz de Tenerife: Melusina.

Mészáros, I. (2010). Más allá del capital. Hacia una teoría de la transición. La Paz: Pasado y Presente XXI.

Schwab, K. (2016). La cuarta revolución industrial. Barcelona: Debate. 


\section{Morfología del tRABAjo EN El CAPITALISMO GLOBAL}

Smith, J. (2016). «Imperialismo en el siglo XXI». Estudios Criticos del Desarrollo, VI(10).

Sotelo, A. (2015). El precariado. ¿Nueva clase social?. México: Miguel Ángel Porrúa.

Sotelo, A. (2019). Estados Unidos en un mundo en crisis. Geopolítica de la precariedad y la superexplotación del trabajo. México: Anthropos.

Srnicek, N. (2018). Capitalismo de plataformas. Buenos Aires: Caja Negra.

Standing, G. (2013). El precariado. Una nueva clase social. Pasado y Presente.

Vía Campesina (2011). «La agricultura campesina sostenible puede alimentar al mundo». Recuperado de http://www.ecoportal.net/TemasEspeciales/Desarrollo-Sustentable/La_agricultura_campesina_sostenible _puede_alimentar_al_mundo

Vincent, J. (1993[2]). «Les automatismes sociaux et le general intellect». Paradigmes du travail, futur antérieur (París: L'Harmattan), 16. Citado por Antunes (2009), «Diez tesis sobre el trabajo del presente (y el futuro del trabajo) ». En Neffa, Julio, De la Garza, Enrique y Muñiz, Leticia (coords.), Trabajo, empleo, calificaciones profesionales, relaciones de trabajo e identidades laborales. Buenos Aires: Clacso.

Womack, J. y Roos (1990). The machine that changed the world: the story of lean production. Toyota's secret weapon in the global car wars that is now revolutionizing world industry. Free Press.

Zuazo, N. (2018). Los dueños de internet. Cómo nos dominan los gigantes de la tecnología y qué hacer para cambiarlo. Buenos Aires: Debate. 